\title{
Full title: An agent-based model of insect resistance management and mitigation for Bt maize: A social science perspective
}

\section{Short title: Agent-based model of insect resistance management and mitigation for Bt Maize}

Yuji Saikai, ${ }^{1}$ Terrance M. Hurley² and Paul D. Mitchell ${ }^{*}$

${ }^{1}$ Agricultural and Applied Economics, University of Wisconsin, Madison, WI, U.S.A.

${ }^{2}$ Applied Economics, University of Minnesota, St. Paul, MN, U.S.A.

*Corresponding author

427 Lorch Court

This is the author manuscript accepted for publication and has undergone full peer review but has not been through the copyediting, typesetting, pagination and proofreading process, which may lead to differences between this version and the Version of Record. Please cite this article as doi: $10.1002 /$ ps.6016

This article is protected by copyright. All rights reserved. 
Madison, WI 53705

Phone: 608-265-6514

Email:pdmitchell@wisc.edu

This article is protected by copyright. All rights reserved. 


\title{
An agent-based model of insect resistance management and mitigation for Bt maize:
}

\section{A social science perspective}

\begin{abstract}
BACKGROUND: Farmers around the world have used Bt maize for more than two decades, delaying resistance using a high-dose/refuge strategy. Nevertheless, field-evolved resistance to Bt toxins has been documented. This paper describes a spatially explicit population genetics model of resistance to Bt toxins by the insect Ostrinia nubilalis and an agent-based model of farmer adoption of Bt maize incorporating social networks. The model was used to evaluate multiple resistance mitigation policies, including combinations of increased refuges for all farms, localized bans on Bt maize where resistance develops, areawide sprays of insecticides on fields with resistance, and taxes on Bt maize seed for all farms. Evaluation metrics included resistance allele frequency, pest population density, farmer adoption of Bt maize and economic surplus.

RESULTS: The most effective mitigation policies for maintaining a low resistance allele frequency were 50\% refuge and localized bans. Areawide sprays were the most effective for maintaining low pest populations. Based on economic surplus, refuge requirements were the recommended policy for mitigating resistance to high-dose Bt maize. Social networks further enhanced the benefits of refuges relative to other mitigation policies but accelerated the emergence of resistance.
\end{abstract}

This article is protected by copyright. All rights reserved. 
CONCLUSION: These results support using refuges as the foundation of resistance mitigation for high-dose Bt maize, just as for resistance management. Other mitigation policies examined were more effective but more costly. Social factors had substantial effects on the recommended management and mitigation of insect resistance, suggesting that agent-based models can make useful contributions for policy analysis.

Keywords. European corn borer, population genetics model, social networks, technology adoption, resistance mitigation policies.

\section{Introduction}

Globally, farmers have planted more than 2.3 billion hectares of genetically engineered crops since commercial introduction in 1996 [1]. In 2017, the United States (US), Brazil and Argentina produced almost half of the world's leading grain crop - maize (Zea mays) [2]. Bt maize, genetically engineered to produce Bacillus thuringiensis (Bt) toxins in plant tissues for insect control, accounted for more than $80 \%$ of the maize planted in these three nations in 2017 [1]. Insect resistance to Bt toxins continues to be a global concern [3], with a high-dose/refuge resistance management strategy the primary policy in multiple nations for delaying resistance to these toxins [4-6]. Nevertheless, field-evolved resistance to some Bt toxins has been documented for some pest populations [7-11].

Bioeconomic models integrating population genetics and pest ecology with farmer returns contributed to developing insect resistance management policies [12-19].

This article is protected by copyright. All rights reserved. 
However, examining genetic and ecological processes in isolation from broader social factors driving human behavior potentially misses key determinants in the evolution of resistance, such as the effects of prices and costs, farmer concerns for human and environmental safety, the opinions of advisors and neighbors, and regulation enforcement. For example, farmer concerns for human and environmental safety are key concerns in adoption of pest management practices, while compliance with refuge is primarily a social outcome that contributes significantly to resistance evolution [20]. Initially low refuge compliance contributed to the development of Bt maize resistance among Busseola fusca populations in South Africa, use of voluntary refuge compliance led low compliance and the same outcome for Spodoptera frugiperda populations in Brazil, while ensuring higher refuge compliance was a significant benefit for use of seed mixtures in the US [21-22]. Hence, complex systems models of resistance management incorporating both biological and social processes may provide new insights [23].

The US Environmental Protection Agency (EPA) required companies to develop resistance mitigation plans as a condition for product registration [24]. Once a resistant population has been documented according to the EPA process, these resistance mitigation plans generally restrict technology availability (Bt seed) around the location where the resistant population emerges. Though resistant populations and field failures have been documented for major pests in the Midwest and Nova Scotia [7-9], EPA criteria have yet to trigger these mitigation plans, with the EPA instead requiring a more generalized response 
by registrants [25]. Research evaluating these or other mitigation plans, particularly from an economic perspective, is lacking. However, because Bt crops have been used for more than two decades, resistance is likely to become an increasing problem, making research on mitigation responses and strategies especially timely.

Agent-based modeling has been used to study complex systems and emergent behavior, including insect resistance [26-30]. In agent-based models, phenomena emerge from interactions among heterogeneous agents in a dynamically evolving environment. Agents typically follow simple decision rules and influence each other directly or indirectly through the environment, which evolves according to its own rules and agent actions. Because modeled processes are complex, researchers use simulations as in silico experiments to examine outcomes over a range of parameter values.

This paper has two goals. First, it describes an agent-based model of insect resistance to Bt maize incorporating farmer adoption behavior and uses it to evaluate mitigation policies. Second, it shows that social network effects on farmer adoption can play a key role in the evolution of resistance by developing a richer social model than used in existing models [31-34]. The bioeconomic model of maize production includes the option to use Bt maize to manage European corn borer (Ostrinia nubilalis), with the adoption model calibrated to aggregate historical adoption data for farmers in the state of Wisconsin. Various resistance mitigation policies are then simulated over the landscape or around locations where resistance develops. To assess the relative performance of each 
policy, economic surplus is used as a monetary measure of the social value generated from using Bt maize.

\section{Materials and Methods}

\section{Landscape Model}

The model uses a $30 \times 70$ grid space representing Wisconsin cropland, with $44 \%$ of the landscape planted to maize [35]. Fields are randomly assigned to maize or non-maize at the start of a simulation and maintain this assignment throughout a run. Maize farmers decide adoption of Bt maize each simulated year. Figure 1 depicts a typical model landscape, in this case with $59 \%$ Bt adoption and a resistance allele frequency of $41 \%$ for the population. A circle (O) represents a farmer who plants conventional (non-Bt) maize, whereas a black $\operatorname{dot}(\mathbf{O})$ represents a farmer who adopts Bt maize. A lightgray background ( $\square$ ) indicates that the pest population in an individual field before adult dispersal has a resistance allele frequency exceeding 50\%, the criterion used for declaring a resistant population [36]. To avoid boundary effects, top fields wrap to corresponding bottom fields and left-most fields to corresponding right-most fields, creating a torus, implying that the model space is part of a larger landscape with comparable dynamics occurring for the pest population and its genetic structure [34].

\section{Pest Population Genetics}

This article is protected by copyright. All rights reserved. 
The pest population-genetics model is parametrized for European corn borer (Ostrinia nubilalis), a major pest for Midwestern maize and a primary target for Bt maize [37]. The model uses discrete time steps corresponding to distinct generations and consistent with the crop production and pest life cycles. O. nubilalis typically has two generations annually in major US maize production regions, though northern regions may have only one generation and southern regions may have three or more [38]. The model simplifies these dynamics to one discrete time step per year that aggregates population dynamics and genetic selection across these generations. A comparable empirical approach was used to estimate annual population growth rates for $O$. nubilalis using annual observations of second-generation adult population densities in Minnesota and Wisconsin [37].

Historically, the $O$. nubilalis population in the Midwestern US has oscillated with an approximately seven year cycle largely due to the entomopathogenic parasite Nosema pyrausta $[39,40]$. Field data for second-generation populations in Wisconsin over 19441995 show an average peak and trough for the oscillation of about 1.2 and 0.2 larvae per plant $[37,40]$. These dynamics are approximated using a lagged logistic growth model:

$$
N_{t+1}=g N_{t}\left(1-\frac{N_{t-1}}{K}\right)
$$

where $N_{t}$ is the second-generation larval population (larvae per maize plant), $g$ is the annual growth rate and $K$ is the carrying capacity. Using $g=2.15$ and $K=1.4$ generates a reasonable approximation of historical $O$. nubilalis population dynamics in Wisconsin, with 
a similar range of population minimums and maximums as observed and six or seven years between peaks.

The genetics model assumes two alleles, $R$ for resistant and $S$ for susceptible, creating three genotypes, homozygous resistant $R R$, homozygous susceptible $S S$, and heterozygous $R S$, with respective Bt toxin larval survival rates of 1.0, 0.0, and 0.18. Each period, after Bt toxin mortality and density-dependent mortality for larvae, random mating occurs among the adult population within each field before adult dispersal. Let $\alpha_{t}, \beta_{t}$, and $\gamma_{t}$ respectively denote the relative frequencies in period $t$ of $R R, S S$, and $R S$ genotypes. Random mating under Hardy-Weinberg equilibrium then implies $1=\alpha_{t+1}+\beta_{t+1}+\gamma_{t+1}=$

$$
\begin{gathered}
\left(\alpha_{t}+\beta_{t}+\gamma_{t}\right)^{2}=\left(\alpha_{t}+0.5 \gamma_{t}\right)^{2}+\left(\beta_{t}+0.5 \gamma_{t}\right)^{2}+2\left(\alpha_{t}+0.5 \gamma_{t}\right)\left(\beta_{t}+0.5 \gamma_{t}\right), \text { so that } \\
\alpha_{t+1}=\left(\alpha_{t}+0.5 \gamma_{t}\right)^{2}, \\
\beta_{t+1}=\left(\beta_{t}+0.5 \gamma_{t}\right)^{2}, \\
\gamma_{t+1}=2\left(\alpha_{t}+0.5 \gamma_{t}\right)\left(\beta_{t}+0.5 \gamma_{t}\right) .
\end{gathered}
$$

Adults disperse uniformly to other maize fields within a radius $r$. To remain computationally tractable, the model uses a dispersal radius of 3 grid spaces, roughly comparable to $15 \mathrm{~km}$ [31]. If no neighboring fields exist within the dispersal range, adults stay in the same field.

\section{Farmer Behavior}

Individual farmers manage each field, deciding each period whether to plant Bt or non-Bt maize. A number of economic and social factors influence farmers' adoption 
decisions, such as prices and costs, educational attainment, access to labor and capital, environmental considerations, and opinions of advisors and neighbors [41]. Rather than explicitly modeling these multiple factors, agent-based models combine simple behavioral models with suitable random components and let complex phenomena emerge [26].

Though expected profitability greatly influences management decisions in commercial agriculture, local social networks also influence behaviors, not just by providing information regarding the relative profitability of different practices [42-44]. Therefore, we model Bt adoption as a hybrid of individual profit maximization and local imitation to capture the effect of social networks.

The profit-based component of farmer behavior uses a switching function [31]:

$$
\operatorname{Pr}(\text { Switch C to } A)=\left\{\begin{array}{ll}
1-\exp \left[-\rho\left(\pi_{A}-\pi_{C}\right)\right] & \text { if } \pi_{A}>\pi_{C} \\
0 & \text { otherwise }
\end{array} .\right.
$$

Here, $\pi_{A}$ is profit for the alternative choice and $\pi_{C}$ is profit for the current choice, with both profits calculated using the field's pest population density from the previous period. The function determines the probability that the farmer switches from the current choice to the alternative (Switch $C$ to $A$ ), with the probability increasing as the alternative becomes relatively more profitable than the current choice. We use a "soft" probabilistic switching rule to capture the effect of other unobserved individual factors [31]. The parameter $\rho$ captures the responsiveness of farmer adoption to profit differences, with a greater $\rho$ increasing the probability farmers use the more profitable alternative. As explained in the Calibration section, $\rho$ is calibrated against the Bt seed adoption data for Wisconsin to 
derive $\rho=0.0036$. The negative-exponential function implies that the switching probability is the farmers' expected utility gain from switching when the gain is uncertain, assuming constant absolute risk aversion, a common empirical assumption $[45,47]$.

Farmer profit for a field $(\pi)$ is crop revenue minus cost, where revenue declines as the pest population increases and cost varies with the scenario:

$$
\pi=P Y(1-\operatorname{Loss}(N))-\text { Cost } .
$$

Here $P$ is crop price $\left(\$ \mathrm{Mg}^{-1}\right), Y$ is potential pest-free crop yield $\left(\mathrm{Mg} \mathrm{ha}^{-1}\right)$, Loss is proportional crop loss, which depends on $N$, the average pest population density (larvae per plant), and Cost is the production cost $\left(\$ \mathrm{ha}^{-1}\right)$. To focus on factors other than annual variability in crop prices and yields, crop price and potential yield are fixed at reported averages in 2017 for Wisconsin farmers: $P=\$ 129.91 \mathrm{ha}^{-1}$ and $Y=10.92 \mathrm{Mg} \mathrm{ha}^{-1}$ [48]. These values imply constant potential revenue of $\$ 1,418.62 \mathrm{ha}^{-1}$ across fields and seasons. As prices and yields vary annually, sensitivity analysis explores the effect of a $\pm 10 \%$ change in crop price (or equivalently yield). The proportion of potential revenue lost due to pest damage depends on the average larval population density based on an empirical model [47]: $\operatorname{Loss}(N)=0.1186 N^{0.5146}$.

Cost consists of a base $\operatorname{cost} C\left(\$ \mathrm{ha}^{-1}\right)$ that does not vary by policy scenario and costs that do:

$$
\text { Cost }=\left\{\begin{array}{ll}
C+T(1-\theta)(1+\tau)+C_{s} & \text { if Bt maize } \\
C+C_{s} & \text { if non-Bt maize }
\end{array} .\right.
$$

This article is protected by copyright. All rights reserved. 
Based on US Department of Agriculture crop budgets [49], the base cost $C$ equals $\$ 1,202.51$ ha $^{-1}$, the average for 2017 in the region containing Wisconsin for all costs except opportunity costs for land and operator labor and management. $T\left(\$ \mathrm{ha}^{-1}\right)$ is the additional seed cost for Bt maize ("technology fee"), which varies over time based on the function estimated with Wisconsin market data [37]. Specially, $T=\$ 17.49$ ha-1 $^{-1}$ from 1996 to 2003, and then declines to $T=\$ 17.45 \mathrm{ha}^{-1}$ for $2004, \$ 17.04 \mathrm{ha}^{-1}$ for $2005, \$ 15.78 \mathrm{ha}^{-1}$ for 2006 , $\$ 13.75 \mathrm{ha}^{-1}$ for $2007, \$ 11.41 \mathrm{ha}^{-1}$ for $2008, \$ 9.18 \mathrm{ha}^{-1}$ for $2009, \$ 8.29 \mathrm{ha}^{-1}$ for $2010, \$ 7.82$ ha-1 for $2011, \$ 7.39 \mathrm{ha}^{-1}$ for 2012 , and then remains at $\$ 7.04$ ha $^{-1}$ for years 2013 and afterward. Remaining cost parameters vary with the policy scenario: $\theta$ is the proportion of refuge (non-Bt maize) planted with $\mathrm{Bt}$ maize, $\tau$ is the tax rate for $\mathrm{Bt}$ maize, and $C_{s}$ is the cost $\left(\$ \mathrm{ha}^{-1}\right.$ ) for a foliar insecticidal spray as part of areawide management of adults. Scenarios set these cost parameters at appropriate values. For example, a refuge only scenario sets $\tau$ $=C_{s}=0$ and sets $\theta$ at $0.05,0.20$ or 0.50 ; a ban only scenario sets $\tau=C_{s}=0$ and $\theta=1(100 \%$ refuge) in fields where a ban is in effect; and an areawide spray policy sets $\tau=0$ and adds the cost $C_{S}$ to all affected fields. The cost of an insecticidal spray $C_{S}$ is $\$ 33.51 \mathrm{ha}^{-1}$ based on published survey averages for insecticide active ingredients used in maize and application costs, adjusted for inflation to 2017 equivalents [50,51].

\section{Social Networks}

In the context of this model, social networks are interpersonal communication systems among individuals (relatives, friends, acquaintances, professional colleagues) that 
involve sharing of information as well as goods and services. In the context of agriculture, neighboring farmers have been shown to create local environments that affect individual farmer adoption decisions, both broadly and specifically for hybrid maize seed and Bt maize [42,52-54]. To capture this social network effect, the model assumes farmers are connected to farmers in neighboring fields, with the neighborhood size determined by a "radius". Figure 2 shows an example of a size- 2 neighborhood for a farmer with nine neighbors who plant maize, either Bt or non-Bt. Those neighbors themselves have their own neighborhoods, with each connection undirected so that the local social networks tightly overlap. The number of neighbors for a size- $n$ neighborhood can range from 0 to a maximum of $4 n(n+1)$. Considering that $n=3$ gives up to 48 neighbors (implying a substantial computational burden), the model randomly assigns neighborhood sizes to each farmer for all seasons using a uniform distribution over $\{0,1,2\}$.

Given this local social network, each maize farmer annually chooses to grow either Bt or non-Bt maize. A parameter $q$ defines the impact of social networks on farmer adoption decisions. With probability $q$, a farmer focuses solely on individual profits using the switching function and with probability $1-q$ follows the majority choice of his neighbors in the previous season. For example, if the farmer in Figure 2 follows the majority, he plants Bt maize next season because his neighborhood has 5 Bt maize adopters and 4 nonadopters. In the case of a tie, he chooses Bt maize as well. Also, one-third of the farmers randomly have a size-0 neighborhood and so, with no social network, always use the 
switching function. As a result, the probability that a farmer uses the switching function is $q+\frac{1}{3}(1-q)$, while the probability that a farmer has a size-1 neighborhood is $\frac{1}{3}(1-q)$, which is also the probability that a farmer has a size- 2 neighborhood. Thus, the model has two calibration parameters for Bt maize adoption: $q$ defining the impact of social networks and $\rho$ defining the responsiveness of farmers to profit in the switching function.

Lastly, a refuge policy is implemented as a fixed proportion $\theta$ of non-Bt maize with complete compliance by farmers, a "refuge in a bag" [55] policy with Bt and non-Bt maize seeds mixed before purchase. The refuge requirement has two effects in the model. First, the seed cost equals the proportion $(1-\theta)$ of the technology fee $T$ in that period. Second, the effective survival rate of each genotype is the weighted average: $\theta+(1-\theta) s$, where $s$ is the toxin survival rate. That is, with probability $\theta$, any genotype faces non-Bt maize, and with probability $1-\theta$, each genotype survives according to its Bt toxin survival rate. The analysis uses $\theta=0.05$ (the lowest refuge requirement currently in place), with higher levels examined as resistance mitigation policies.

\section{Running and Calibrating the Model}

After initialization, a model run begins by randomly placing farmers across the landscape, then proceeds period by period, with a period corresponding to a growing season. Before introducing Bt maize, the insect module runs for 11 periods, corresponding to the pre-Bt period, to stabilize the model's biological dynamics. Thereafter, the model simultaneously updates the pest population density of each field for each period. First, Bt 
toxin effects reduce each field's pest population based on survival rates of the genotypes established there the previous season. Second, mating determines the genotype composition of the next generation based on random mating of the population in the field. Third, reproduction determines the pest population density based on the lagged logistic growth model. Fourth, the population locally re-mixes across fields based on the dispersal model. Finally, maize farmers simultaneously make planting decisions (whether to plant Bt or non-Bt maize) for the next season based on the farmer behavioral model. Multiple sources of randomness make model runs stochastic, so simulations average key outcome variables over 1,000 runs to report results.

The farmer behavioral model and the social networks model were calibrated to aggregate Bt maize adoption data for Wisconsin. Specifically, the mean squared error (MSE) for a run was the squared deviation of the simulated Bt adoption rate each season from the corresponding annual Wisconsin adoption rate for seasons $t=11$ to 32 . Since runs were stochastic, the MSEs were averaged across 1,000 runs. The calibration parameters were the responsiveness of farmers to expected profit differences between alternatives $(\rho)$ and the probability $(q)$ that farmers focus solely on profit differences to make adoption decisions, rather than their neighbors' choices. Calibration minimized the MSE using a grid search with increments of 0.0002 for $\rho$ and 0.1 for $q$. To highlight the significance of local networks, the model was also calibrated using only $\rho$ after fixing $q=1$ to "shut off" social network effects on adoption.

This article is protected by copyright. All rights reserved. 


\section{Policy Scenarios}

For the baseline scenario, periods 0 to 10 were an initialization phase, periods 11 to 32 were a calibration phase corresponding to years 1996 to 2017, and periods 33 to 60 were projections. In addition, four resistance mitigation scenarios were simulated: increases in non-Bt maize refuges, a tax on Bt maize seed, localized bans on use of Bt maize, and areawide sprays with non-Bt insecticide. Resistance mitigation began in a simulation after period 33 if the R-allele frequency exceeded $50 \%$ in the pest population in a field after Bt toxin mortality and before pest dispersal occurred. Each scenario involved a baseline and two alternative levels for key parameters. Three levels for each of four policies created $3^{4}=81$ mitigation policy combinations to simulate.

The refuge scenario increased the refuge requirement from the baseline of $5 \%$ to either $20 \%$ or $50 \%$ for all farmers on the landscape planting Bt maize, with complete compliance achieved using seed mixtures. The tax policy increased the Bt seed cost by $25 \%$ or $50 \%$ for all farmers on the landscape for all periods after resistance occurred.

The localized ban was imposed on fields within a radius $r$ of any field where resistance occurred, again with complete compliance assumed. Two radii were used: once and twice the distance of adult dispersal from the natal field $(r=1 \times$ dispersal, $r=$ $2 \times$ dispersal). Conceptually, the ban is a $100 \%$ refuge requirement applied locally and dynamically imposed and lifted according to the previous period's situation.

This article is protected by copyright. All rights reserved. 
For areawide management, a non-Bt insecticide was applied in the period when resistance exceeded the threshold, either covering only the field of resistance or all maize fields in a neighborhood around the field within the distance of adult dispersal ( $r=$ $0 \times$ dispersal, $r=1 \times$ dispersal). Complete compliance with the insecticide application for all fields within this area was assumed. The application reduced the pest population by $80 \%$ after Bt toxin mortality and increased farmer costs by $\$ 33.51$ ha $^{-1}$, based on published survey averages for active ingredient and application costs and adjusted for inflation to 2017 equivalents [50,51].

Baseline is the abbreviation for the baseline of $5 \%$ non-Bt refuge, with no areawide insecticidal sprays, localized Bt maize bans, or Bt seed taxes. Other abbreviations denote the policy changed from this baseline, including increasing refuge to $20 \%$ or $50 \%$ (20\% Refuge, $50 \%$ Refuge), increasing Bt seed tax to $25 \%$ or $50 \%$ ( $25 \%$ Tax, $50 \%$ Tax), using insecticidal sprays in the field with resistance or within one dispersal distance of the field with resistance (Spray 0x, Spray 1x) or banning use of Bt maize in fields within one or two dispersal radii of fields with resistance (Ban 1x, Ban 2x).

The calibrated model was run 1,000 times for each scenario and three variables were averaged over all 1,000 iterations for each period: aggregate farmer adoption of $\mathrm{Bt}$ maize, population-level R-allele frequency, and average pest population density for the landscape. In addition, as a performance metric to compare each policy, economic surplus

This article is protected by copyright. All rights reserved. 
each period was approximated as the sum of farmer profits and technology fees collected by the seed company, divided by the total number of farmers.

Costs for spraying insecticides were subtracted from farmer profits for those making applications, while collected taxes were subtracted from farmer profits, but added to economic surplus (i.e., the tax was a surplus transfer, not a surplus loss). To simplify the analysis, future surpluses were not discounted. Each scenario began in period 33 after the calibration phase and the cumulative surplus was evaluated using a planning horizon ranging from 1 to 25 years (periods 33 to 57 ).

\section{Results}

\section{Biological Results}

Figure 3 plots baseline results for the insect population density, the Bt adoption rate, and the resistance allele frequency under the current resistance management policy of 5\% non-Bt refuge, with no areawide insecticidal sprays, localized Bt maize bans, or Bt seed taxes. The baseline model reproduces the previously noted oscillation of the European corn borer population before the advent of Bt maize [40], and the documented suppression of the pest population due to the widespread farmer adoption of Bt maize in Wisconsin and other states [37]. Baseline results suggest that period 33 was the beginning of a significant increase in the R-allele frequency. In period 33, the R-allele frequency was $4.2 \%$, but rose quickly, exceeding $10 \%$ in period $36,20 \%$ in period $38,30 \%$ in period $39,40 \%$ in period 40 
and $50 \%$ in period 41 . The pest population does not recover until later, with the average density not exceeding 0.5 larvae per plant until period 50 .

Figures 4 to 6 plot results for the dynamics for Bt adoption, the R-allele frequency, and the pest population density individually (not combinations of policies). Plots begin with planning horizon year 0, corresponding to period 32 in Figure 3.

Figure 4 plots the Bt adoption rate against the planning horizon for the baseline (Baseline), 20\% refuge (20\% Refuge), 50\% refuge (50\% Refuge), 25\% seed tax (25\% Tax), $50 \%$ seed tax (50\% Tax), areawide spray in the field with resistance (Spray 0x) and a localized ban on Bt seed within one pest dispersal radius of the field with resistance (Ban 1x). Results for the ban policy (Ban 1x) are plotted with a separate vertical axis due to its qualitatively different and much stronger effect than for the other policies. Also, results for the spray policy with $r=1 \times$ dispersal (Spray $1 \mathrm{x}$ ) and the ban policy with $r=2 \times \operatorname{dispersal}$ (Ban $2 x$ ) are omitted as they were similar to results with smaller radii.

Consistent with Figure 3, the baseline policy showed a continuing increase in Bt maize adoption from planning horizon year 0 , with a peak of almost $87.8 \%$ in horizon year 9. All policies showed this same general trend (with one exception), but with a lower adoption peak occurring sooner for the seed tax policies, a higher adoption peak occurring later for the increased refuge policies (especially for $50 \%$ refuge), and a slightly higher and later peak occurring for the areawide spray policies. The exception was localized bans on

This article is protected by copyright. All rights reserved. 
use of Bt seed, which caused a rapid decline in the use of Bt maize and almost complete lack of use by the end of the simulation in horizon year 25 .

Figure 5 plots the R-allele frequency, showing that all mitigation policies slowed the development of resistance compared to the baseline. The most effective mitigation policies were the $50 \%$ refuge for all farms and a localized ban on and around fields with resistance, both of which kept the R-allele frequency below $20 \%$ for more than 20 years. By horizon year 25 , however, the $50 \%$ refuge policy showed a rapid increase in the R-allele frequency, suggesting its failure, while the ban policy kept the frequency below $20 \%$, suggesting that it was the most effective policy for mitigating resistance over the long-run ( $>25$ years). The $20 \%$ refuge for all farms effectively mitigated resistance for about 10 years, and then the Rallele frequency began to rapidly increase, reaching the baseline level by horizon year 25 . The spray policies were not particularly effective for mitigating resistance, showing a steady increase in the R-allele frequency, though slower than for the baseline and tax policies. Both tax policies as they were almost identical to baseline results, suggesting low policy efficacy, which was surprising because Bt adoption differs noticeably for these policies (Figure 4).

Figure 6 (pest population density) shows that the areawide spray policy kept the pest population density low over all 25 years, even with a radius $=0$, due to the efficacy of the insecticide spray. The baseline with no intervention to mitigate resistance kept the pest population density low for about 15 years, and then the population increased and began to 
oscillate as expected. Surprisingly, the refuge policies showed distinctly different patterns over the 25 years. The $20 \%$ refuge policy kept the pest population low for about 20 years (about 5 years longer than the baseline), while the 50\% refuge showed a long slowly increasing pest population density over all 25 years, exceeding the baseline in year 17 and the $20 \%$ refuge policy in year 23 . Interestingly, the ban policy only kept the pest population low for about 10 years (about 5 years longer than the baseline). Again, results for both tax policies were almost identical to baseline results.

These results showed the trade-offs inherent in mitigating resistance. The 50\% refuge and ban policies were the most effective at reducing the frequency of resistance alleles (Figure 5), but this efficacy came at the cost of reduced Bt adoption (Figure 4) and higher pest populations (Figure 6), implying lower benefits. Hence, economic surplus is used to integrate across costs and benefits to compare policies and to develop recommendations.

\section{Economic Results}

Figure 7 plots average annual economic surplus against the planning horizon. Each point on the curves is an annualized average of accumulated surplus over the planning horizon: the sum of landscape surplus over the planning horizon, divided by the number of years in the planning horizon and the maize planted area. Furthermore, annual surpluses are nominal (not adjusted for inflation) and not discounted to present values. The baseline generated the greatest average annual surplus for all planning horizons up to 16 years 
because the surplus measure was cumulative and the baseline accumulated more surplus during the early years than the other policies. However, for planning horizons of 17 or more years, the optimal mitigation policy increased the refuge requirement from $5 \%$ to $20 \%$ for all farms. The ban policy was sub-optimal due to the loss of Bt maize benefits for farmers and lost revenue for seed companies. The $50 \%$ refuge policy generated the lowest economic surplus - though among the most effective policies, the cost of lost farmer benefits was too high. Results for the tax policies as they were almost identical to baseline results.

Table 1 summarizes results over the 81 possible policy combinations, not the single policies in Figure 7 (see supplemental information Table S1 for complete results). Three combinations emerged as optimal depending on the planning horizon. For a planning horizon of 1 to 16 years, the baseline was optimal even as resistance increased. For a planning horizon of 17 to 23 years, the optimal policy increased the refuge requirement from $5 \%$ to $20 \%$. For a planning horizon of 24 to 25 years, adding a $50 \%$ tax and making areawide insecticide applications where resistance emerged to the $20 \%$ refuge requirement was optimal, but the increase in economic surplus was trivial $(<0.5 \%)$. A localized ban or an areawide spray was never part of the optimal policy. These results suggest that the optimal resistance mitigation policy is no intervention for a shorter $(\leq 16$ years) planning horizon and, for longer ( $\geq 17$ years) planning horizons, increasing refuges (to $20 \%$ for all farmers) when resistance emerges. Increasing refuges decreases current 
benefits to achieve greater future benefits. Discounting future benefits implies that the refuge policies would generate less surplus than plotted in Figure 7. Calculations showed that with a $14 \%$ or higher discount rate, the baseline remained the optimal policy for all planning horizons of 25 or more years.

The effect of a $\pm 10 \%$ change in crop price (or equivalently yield) had minor effects on results. Higher prices accelerate Bt adoption, leading to lower pest population densities initially, more rapid evolution of resistance and quicker recovery of population densities. In terms of optimal mitigation policies, higher crop prices make the baseline policy optimal for slightly longer time horizons and more active policies (using taxes and areawide sprays) optimal for longer planning horizons, but with relatively small differences between

policies. Overall, results showed only minor sensitivity to crop price and yield assumptions.

\section{Role of Social Networks}

Figures 8 and 9 show results with social networks "shut off" when farmers made Bt adoption decisions without considering the adoption decisions of their neighbors (to simulate a lack of communication). Farmer adoption without social networks was initially faster, but then slowed and eventually declined from period 45 onward (Figure 8). Without social networks, profitable adoption by early users was not slowed by neighboring nonadopters, then as Bt maize became less profitable due to resistance, abandonment of $\mathrm{Bt}$ maize was not slowed by neighboring adopters. With less use of Bt maize, the R-allele frequency remained low for longer than for the baseline, slowing the evolution of 
resistance by about 3 years. Hence, these results suggest that social networks accelerate the development of resistance by delaying abandonment of Bt maize as resistance emerges and it becomes unprofitable.

Figure 9 plots average annual economic surplus against the planning horizon without social networks. Again, results for tax policies are omitted as they were almost identical to the baseline, and annual surpluses are nominal undiscounted. All mitigation policies generated roughly equivalent surplus for the first 6 or 7 years because the slower evolution of resistance without social networks delayed policy implementation. The optimal policy depended on the planning horizon, with the baseline optimal for planning horizons up to 17 years, about the same as with social networks (Figure 7). For planning horizons exceeding 17 years, the areawide spray policy became optimal because without social networks, farmers more quickly stopped using Bt maize when resistance developed, thus avoiding the higher costs of spraying and lower Bt maize benefits. The difference between the baseline (with $5 \%$ refuge) and the $20 \%$ refuge policy is much smaller than with social networks (Figure 7), and again, the ban and 50\% refuge policies generated the lowest economic surplus over many planning horizons.

Table 2 summarizes results over the 81 possible policy combinations, not the single policies in Figure 9 (see supplemental information Table S2 for complete results). For a planning horizon of 1 to 17 years, the baseline policy continued to be optimal even as resistance increased. For planning horizon of 18 to 25 years, the optimal resistance

This article is protected by copyright. All rights reserved. 
mitigation policy was to again use $5 \%$ refuges for all farmers, to add a $50 \%$ Bt maize seed tax on all farmers, and to make areawide insecticide applications where resistance emerged. Without social networks, the greater farmer responsiveness to profitability made more active mitigation policies optimal for longer planning horizons. However, the effect was not large, as again calculations showed that with a $18 \%$ or higher discount rate, the baseline remained the optimal policy for all planning horizons less than 25 years.

\section{Discussion and Conclusion}

This paper demonstrated that an agent-based model can produce policy-relevant results. The model examined resistance mitigation policies for Bt maize and the European corn borer while incorporating social network effects on Bt maize adoption. The analysis evaluated 81 resistance mitigation policies that combined up to four policies (non-Bt maize refuge, areawide non-Bt insecticide sprays, localized Bt maize bans, and Bt maize seed tax) with three levels, implemented when and/or where resistance emerged. These combinations showed variation in projected dynamics for Bt maize adoption, resistance allele frequency, average pest population density, and economic surplus generated.

The most effective mitigation policies for keeping the frequency of resistance alleles low were a 50\% refuge requirement for all farms when resistance emerged and a localized ban on planting Bt maize within one radius of adult dispersal of farms with resistance. However, optimal responses change when using a broader economic perspective that balances costs and benefits by maximizing economic surplus - the sum of farmer profit

This article is protected by copyright. All rights reserved. 
from maize production, company technology fees from selling Bt maize seed, and tax revenue. When resistance emerges, the optimal mitigation policy was making no policy changes, but continuing the current resistance management policy of 5\% non-Bt refuge, with no areawide insecticidal sprays, localized Bt maize bans, or Bt seed taxes. For longer planning horizons ( $\geq 17$ years), increasing refuge requirements to $20 \%$ for all farmers became optimal when resistance developed, but only for discount rates below $14 \%$. A localized ban and a 50\% refuge policy were not optimal for any planning horizons, as the costs outweighed the benefits.

Several caveats apply. The model assumes one single-toxin Bt maize producing a high dose. However, multiple single-toxin Bt maize hybrids with different modes of action have been commercialized in the US, with single-toxin Bt maize hybrids mostly phased out as companies have shifted to pyramiding multiple Bt traits [56]. Furthermore, refuge requirements have changed. Initial requirements were for $20 \%$ non-Bt maize as structured refuges, but some Bt maize hybrids with pyramided traits currently have a $5 \%$ or $10 \%$ refuge requirement implemented as a seed mix and/or structured refuges $[38,56]$. The model does not capture the use of multiple toxins entering the market at different times, overlapping use of hybrids with multiple, pyramided traits by neighbors, or changes in refuge requirements since commercialization. The model also assumes that Bt maize delivers a high toxin dose, which is accurate for European corn borer, but not for corn earworm (Helicoverpa zea) or the corn rootworm complex (genus Diabrotica) [57-59]. 
Furthermore, the model focuses on a single pest, though farmers simultaneously manage multiple pests with varying levels of control by different Bt maize hybrids [38]. The model also assumes a single selection by Bt toxin each year, while many target pests, including the European corn borer, have multiple generations per season with more than one $\mathrm{Bt}$ selection event [38]. Also, economic surplus is an incomplete measure of social benefits [60]. For example, as used here, it ignores the environmental impacts of insect management, though a significant benefit of Bt maize is that it substitutes for conventional insecticides [61-63]. With these caveats, the policy experiments reported here support refuge requirements as the foundation of resistance mitigation policies for high-dose technologies, just as for resistance management.

This paper also demonstrated that social factors can play key roles in the development and management of insect resistance. To capture the effect of social networks, individual farmer adoption of Bt maize depended on both their expected profitability and adoption by their neighbors. Relative to a model with adoption only depending on individual profitability, social networks impeded farmer responsiveness to profitability, which initially slowed both adoption of Bt maize and later abandonment of it as the pest population declined and resistance developed. As a result, the model projected that resistance developed about 3 years earlier with social network effects than without because farmers used Bt maize more intensely - they did not stop using it when profitability decreased as the pest population declined and resistance developed. The 
optimal resistance mitigation policy favored use of refuge policies both with and without social network effects, but the difference in social surplus between the baseline and with increased refuges was much larger with social networks than without. Also, with longer planning horizons, social networks reduced the relative value of active policies (seed taxes, areawide sprays). In this example, ignoring social network effects contributed to inaccurate projections for the development of resistance and recommended mitigation policies.

Many social factors not addressed here also affect adoption, including commodity markets, farmer preferences for managing income risk and for human and environmental safety $[20,45,46]$, and technology markets and seed company pricing behavior [64]. Also, social networks in agriculture typically have varying nodes of importance centered on key consultants, retailers, and extension agents $[42,43]$. Social factors also affect resistance through more than just adoption, such as through compliance with resistance management and mitigation policies and crop rotation $[12,65]$. Nevertheless, more applied and quantitative social science research, including use of agent-based models, can contribute to developing better policy recommendations for resistance management and mitigation.

\section{Acknowledgments}

We acknowledge the editorial assistance of William Hutchison. This research was funded in part by the U.S Department of Agriculture National Institute for Food and Agriculture's Agriculture and Food Research Initiative (grant number 2014-67023-21814) and Monsanto's Corn Rootworm Knowledge Research Program.

This article is protected by copyright. All rights reserved. 


\section{References}

1. International Service for the Acquisition of Agri-biotech Applications, Global status of commercialized biotech/GM crops in 2017: biotech crop adoption surges as economic benefits accumulate in 22 Years, report no. 53 (2018).

https://www.isaaa.org/resources/publications/briefs/53/executivesummary/default .asp [accessed 18 March 2020]

2. US Department of Agriculture. World agricultural supply and demand estimates, report no. 581 (2018). https://www.usda.gov/oce/commodity/wasde/ [accessed 18 March 2020]

3. Tabashnik BE, ABCs of insect resistance to Bt. PLOS Genet 11: e1005646 (2015).

4. Huang F, Andow DA, Buschman LL, Success of the high-dose/refuge resistance management strategy after 15 years of Bt crop use in North America. Entomol Exp Appl 140: 1-16 (2011).

5. Pardo-López L, Soberón M, Bravo A, Bacillus thuringiensis insecticidal three-domain Cry toxins: mode of action, insect resistance and consequences for crop protection. FEMS Microbiol Rev 37: 3-22 (2013).

6. Tabashnik BE, Brévault $T$, Carrière $Y$, Insect resistance to Bt crops: lessons from the first billion acres. Nat Biotech 31: 510-521 (2013).

7. Gassmann AJ, Petzold-Maxwell JL, Keweshan RS, Dunbar MW, Field-evolved resistance to Bt maize by western corn rootworm. PLOS ONE 6: e22629 (2011).

8. Gassmann A, Petzold-Maxwell J, Clifton E, Dunbar M, Hoffmann A, Ingber D, Keweshan $\mathrm{R}$, Field-evolved resistance by western corn rootworm to multiple Bacillus thuringiensis toxins in transgenic maize. Proc Natl Acad Sci 111: 5141-5146 (2014).

9. Smith JL, Farhan Y, Schaafsma AW. Practical Resistance of Ostrinia nubilalis (Lepidoptera: Crambidae) to Cry1F Bacillus thuringiensis maize discovered in Nova Scotia, Canada. Sci Rep 9: 18247 (2019).

10. Tabashnik BE, Carrière $Y$, Surge in insect resistance to transgenic crops and prospects for sustainability. Nat Biotechnol 35: 926-935 (2017).

This article is protected by copyright. All rights reserved. 
11. Tabashnik BE, Carrière Y, Global patterns of resistance to Bt crops highlighting pink bollworm in the United States, China, and India. J Econ Entomol 112: 2513-2523 (2019).

12. Hurley TM, Babcock BA, Hellmich RL, Bt corn and insect resistance: an economic assessment of refuges. J Agric Resour Econ 26: 176-194 (2001).

13. Crowder D, Onstad D, Gray M, Mitchell P, Spencer J, Brazee R, Economic analysis of dynamic management strategies utilizing transgenic corn for control of western corn rootworm (Coleoptera: Chrysomelidae). J Econ Entomol 98: 961-975 (2005).

14. Mitchell PD, Onstad DW, Effect of extended diapause on evolution of resistance to transgenic Bacillus thuringiensis corn by northern corn rootworm (Coleoptera: Chrysomelidae). J Econ Entomol 98: 2220-2234 (2005).

15. Hurley TM, Babcock BA, Hellmich RL, Bt corn and insect resistance: an economic assessment of refuges. J Agric Resour Econ 26: 176-194 (2001).

16. Hyde J, Martin MA, Preckel PV, Edwards CR, The economics of Bt corn: valuing protection from the European corn borer. Rev Agric Econ 21: 442-454 (1999).

17. Livingston MJ, Carlson GA, Fackler PL, Managing resistance evolution in two pests to two toxins with refugia. Amer J Agric Econ 86: 1-13 (2004).

18. Livingston MJ, Fernandez-Cornejo J, Frisvold GB, Economic returns to herbicide resistance management in the short and long run: the role of neighbor effects. Weed Sci 64(SP1): 595-608 (2016).

19. Mitchell PD, Hurley TM, Babcock BA, Hellmich RL, Insuring the Stewardship of Bt Corn:'A Carrot'versus' A Stick'. J Agric Resour Econ 27: 390-405 (2002).

20. Hurley TM, Mitchell PD, The value of insect management to U.S. maize, soybean and cotton farmers, Pest Manag Sci Forthcoming (2020).

21. Kruger M, Van Rensberg JBJ, Van Den Berg J, Transgenic Bt maize: farmers' perceptions, refuge compliance and reports of stem borer resistance in South Africa.J Appl Entomol 136: 38-50 (2012).

22. Monnerat R, Martins E, Macedo C, Queiroz P, Praça L, Soares CM, Moreira H, Grisi I, Silva J, Soberon M, Bravo A, Evidence of field-evolved resistance of Spodoptera

This article is protected by copyright. All rights reserved. 
frugiperda to Bt corn expressing Cry1F in Brazil That is still sensitive to modified $\mathrm{Bt}$ toxins. PLOS ONE 10: e0119544 (2015).

23. Rebaudo F, Dangles 0, An agent-based modeling framework for integrated pest management dissemination programs. Environ Model Software 45: 141-149 (2013).

24. US Environmental Protection Agency, Biopesticides registration action documents: Cry1 Ab and Cry1F Bacillus thuringiensis (Bt) corn plant-incorporated protectants (2010). https://www3.epa.gov/pesticides/chem_search/reg_actions/pip/cry1fcry1ab-brad.pdf [accessed 18 March 2020]

25. Andow D, Pueppke S, Schaafsma A, Gassmann A, Sappington T, Meinke L, Mitchell P, Hurley M, Hellmich R, Porter P, Early detection and mitigation of resistance to Bt maize by western corn rootworm (Coleoptera: Chrysomelidae). J Econ Entomol 109: 1-12 (2016).

26. Miller JH, Page SE, Complex Adaptive Systems: An Introduction to Computational Models of Social Life. Princeton University Press, Trenton, NJ (2009).

27. Peck SL, Simulation as experiment: a philosophical reassessment for biological modeling. Trends Ecol Evol 19: 530-534 (2004).

28. Renton M, Shifting focus from the population to the individual as a way forward in understanding, predicting and managing the complexities of evolution of resistance to pesticides. Pest Manag Sci 69: 171-175 (2013).

29. Renton M, Busi R, Neve P, Thornby D, Vila-Aiub M, Herbicide resistance modelling: past, present and future. Pest Manag Sci 70: 1394-1404 (2014).

30. Gay P-E, Lecoq M, Piou C, Improving preventive locust management: insights from a multi-agent model. Pest Manag Sci 74: 46-58 (2017).

31. Milne A, Bell J, Hutchison W, van den Bosch F, Mitchell P, Crowder D, Parnell S, Whitmore A, The effect of farmers' decisions on pest control with Bt crops: a billion dollar game of strategy. PLOS Comput Biol 11: e1004483 (2015).

32. Ives A, Paull C, Hulthen A, Downes S, Andow D, Haygood R, Zalucki M, Schellhorn N, Spatio-temporal variation in landscape composition may speed resistance evolution of pests to Bt crops. PLOS ONE 12: e0169167 (2017).

This article is protected by copyright. All rights reserved. 
33. Onstad DW, Meinke LJ, Modeling evolution of Diabrotica virgifera virgifera (Coleoptera: Chrysomelidae) to transgenic corn with two insecticidal traits.J Econ Entomol 103: 849-860 (2010).

34. Storer NP, A spatially explicit model simulating western corn rootworm (Coleoptera: Chrysomelidae) adaptation to insect-resistant maize. J Econ Entomol 96: 1530-1547 (2003).

35. USDA. 2012 census of agriculture (2012).

https://www.agcensus.usda.gov/Publications/2012/ [accessed 18 March 2020]

36. Tabashnik BE, Delaying insect resistance to transgenic crops. Proc Natl Acad Sci 105: 19029-19030 (2008).

37. Hutchison WD, Burkness EC, Mitchell PD, Moon RD, Leslie TW, Fleischer SJ, et al., Areawide suppression of European corn borer with Bt maize reaps savings to non-Bt maize growers. Science 330: 222-225 (2010).

38. Mason CE, Rice ME, Calvin DD, Van Duyn JW, Showers WB, Hutchison WD, et al., European Corn Borer Ecology and Management. Iowa State University, Ames, IA (1996).

39. Onstad DW, Maddox JV, Modeling the effects of the microsporidium, Nosema pyrausta, on the population dynamics of the insect Ostrinia nubilalis. J Invertebr Pathol 53: 410421 (1989).

40. Bell JR, Burkness EC, Milne AE, Onstad DW, Abrahamson M, Hamilton KL, Hutchison WD, Putting the brakes on a cycle: bottom-up effects damp cycle amplitude: managing epidemic persistence. Ecol Lett 15: 310-318 (2012).

41. Useche P, Barham BL, Foltz JD, Integrating technology traits and producer heterogeneity: a mixed-multinomial model of genetically modified corn adoption. Amer J Agric Econ 91: 444-461 (2009).

42. Kaup BZ, The reflexive producer: the influence of farmer knowledge upon the use of Bt corn. Rural Sociol 73: 62-81 (2008).43. L Lubell M, Fulton A, Local policy networks and agricultural watershed management. J Public Adm Res Theory 18: 673-696 (2007).

44. McAllister R, Robinson C, Maclean K, Guerrero A, Collins K, Taylor B, De Barro P, From local to central: a network analysis of who manages plant pest and disease outbreaks across scales. Ecol Socty 20: 67 (2015).

This article is protected by copyright. All rights reserved. 
45. Chavas J-P, Risk analysis in Theory and Practice. Academic Press, Cambridge (2004).

46. Mitchell PD, Hutchison WD, Decision making and economic risk in IPM, in Integrated Pest Management: Concepts, Tactics, Strategies and Case Studies, ed. by Radcliffe EB, Cancelado RE, Hutchison WD, Cambridge University Press, Cambridge, pp. 33-50 (2008).

47. Hurley TM, Mitchell PD, Rice ME, Risk and the value of Bt corn. Amer J Agric Econ 86: 345-358 (2004).

48. United States Department of Agriculture National Agricultural Statistics Service (USDA-NASS), Quick stats tool. USDA-NASS, Washington, DC (2010). Available: http://quickstats.nass.usda.gov/ [18 March 2020].

49. US Department of Agriculture, Commodity costs and returns (2020). http://www.ers.usda.gov/data-products/commodity-costs-and-returns/commoditycosts-and-returns/\#Recent Costs and Returns: Corn [accessed 18 March 2020]

50. Mitchell PD, Methods and assumptions for estimating the impact of pyrethroid insecticides on pest management practices and costs for U.S. crop farmers (2017). http://aginfomatics.com/pyrethroids-project.html [accessed 18 March 2020]

51. US Department of Agriculture, Agricultural prices (2020). https://usda.library.cornell.edu/concern/publications/c821gj76b [accessed 18 March 2020]

52. Ryan B, Gross NC, The diffusion of hybrid seed corn in two Iowa communities. Rural Sociol 8: 15 (1943).

53. Maertens A, Barrett CB, Measuring social networks' effects on agricultural technology adoption. Amer J Agric Econ 95: 353-359 (2013).

54. Bandiera 0, Rasul I, Social networks and technology adoption in northern Mozambique. Econ J 116: 869-902 (2006).

55. Hodgson E, Refuge in a bag is here: explaining the simplified refuge (2010). https://crops.extension.iastate.edu/cropnews/2010/06/refuge-bag-here-explainingsimplified-refuge [accessed 18 March 2020]

56. US Environmental Protection Agency, Insect resistance management for Bt plantincorporated protectants (2019). https://www.epa.gov/regulation-biotechnology-

This article is protected by copyright. All rights reserved. 
under-tsca-and-fifra/insect-resistance-management-bt-plant-incorporated [accessed 18 March 2020]

57. US Environmental Protection Agency, White paper on resistance in Lepidopteran pests of Bacillus thuringiensis (Bt) plant-incorporated protectants in the United States (2018). https://www.epa.gov/sites/production/files/201807/documents/position_paper_07132018.pdf [accessed 18 March 2020]

58. Burkenss EC, Dively G, Patton T, Morey AC, Hutchinson WD, Novel Vip3A Bacillus thuringiensis (Bt) maize approaches high-dose efficacy against Helicoverpa zea (Lepidoptera: Noctuidae) under field conditions: implications for resistance management. GM Crops 1: 337-343 (2010).

59. Gassmann AJ, Petzold-Maxwell JL, Clifton EH, Dunbar MW, Hoffmann AM, Ingber DA, Keweshan RW, Field-evolved resistance by western corn rootworm to multiple Bacillus thuringiensis toxins in transgenic maize. Proc Natl Acad Sci 111: 5141-5146 (2014).

60. Mitchell PD, Brown Z, McRoberts N, Economic issues to consider for gene drives. J Responsible Innov 5(sup1): S180-202 (2018).

61. Perry E, Ciliberto F, Hennessy D, and Moschini G, Genetically engineered crops and pesticide use in U.S. maize and soybeans. Sci Adv 2: e1600850 (2016).

62. Catarino R, Areal F, Park J, Parisey N, Spatially explicit economic effects of nonsusceptible pests' invasion on Bt maize. Agric Syst 175: 22-33 (2019).

63. Brookes G, Twenty-one years of using insect resistant (GM) maize in Spain and Portugal: farm-level economic and environmental contributions. GM Crops Food 10: 90-101 (2019).

64. Shi G, Chavas J, Stiegert K, An analysis of the pricing of traits in the U.S. corn seed market. Am J Agric Econ 92: 1324-1338 (2010).

65. Hurley TM, Mitchell PD, Insect resistance management: Adoption and compliance, in Insect Resistance Management, $2^{\text {nd }}$ ed., ed. by Onstad DW, Academic Press, San Diego, pp. 421-451 (2014).

This article is protected by copyright. All rights reserved. 
Table 1. Optimal policy combination by length of optimization period with social network effects

\begin{tabular}{ccccc}
\hline Length of & Refuge & Localized & Areawide & \\
Optimization Period & Requirement & Ban & Spray & Bt Seed Tax \\
\hline $1-16$ & $5 \%$ & None & None & $0 \%$ \\
$17-23$ & $20 \%$ & None & None & $0 \%$ \\
$24-25$ & $20 \%$ & None & $r=0$ & $50 \%$ \\
\hline
\end{tabular}

Table 2. Optimal policy combination by length of optimization period without social network effects

\begin{tabular}{ccccc}
\hline Length of & Refuge & Localized & Areawide & \\
Optimization Period & Requirement & Ban & Spray & Bt Seed Tax \\
\hline $1-17$ & $5 \%$ & None & None & $0 \%$ \\
$18-25$ & $5 \%$ & None & $r=0$ & $50 \%$ \\
\hline
\end{tabular}

This article is protected by copyright. All rights reserved. 


\begin{tabular}{|c|c|c|c|c|c|c|c|c|c|c|c|c|c|c|c|}
\hline$\bullet$ & $\bullet$ & & & 0 & 0 & 0 & & & & & & • & & & \\
\hline$\bullet$ & & & & & & 0 & 0 & & 0 & 0 & 0 & & & $\bullet$ & $\bullet$ \\
\hline & & & & & & & 0 & & & 0 & 0 & & & & \\
\hline & & 0 & 0 & & & $\bullet$ & 0 & & & 0 & 0 & • & ○ & $\bullet$ & \\
\hline & & 0 & 0 & & & • & • & • & & & & & & $\bullet$ & \\
\hline$\bullet$ & & & & & & & $\bullet$ & 0 & 0 & & 0 & & 0 & 0 & $\bullet$ \\
\hline$\bullet$ & & & & 0 & & & & & & $\bullet$ & $\bullet$ & & $\bullet$ & $\bullet$ & $\bullet$ \\
\hline$\bullet$ & 0 & & & 0 & 0 & 0 & & & & & $\bullet$ & 0 & & & \\
\hline
\end{tabular}

Figure 1. Example model landscape. Circle $(0)$ represents a field planted to non-Bt maize, black dot ( ) represents a field planted to Bt maize, and lightgray ( $\square$ ) indicates a field with a pest population with a resistance allele frequency of more than $50 \%$ before adult dispersal.

This article is protected by copyright. All rights reserved. 


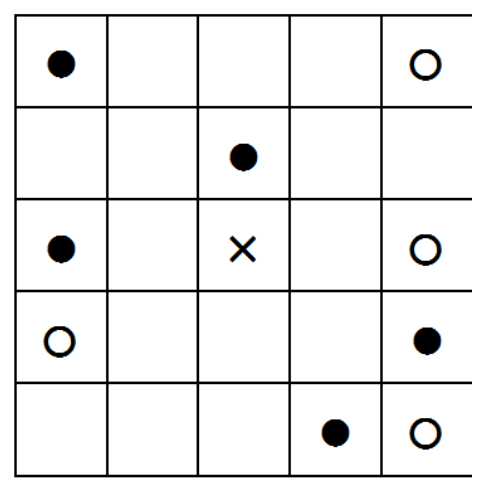

Figure 2. Example size-2 neighborhood centered on a farmer $(\mathbf{x})$ with nine neighbors who plant maize, either Bt maize (O) or non-Bt maize (O)

This article is protected by copyright. All rights reserved. 


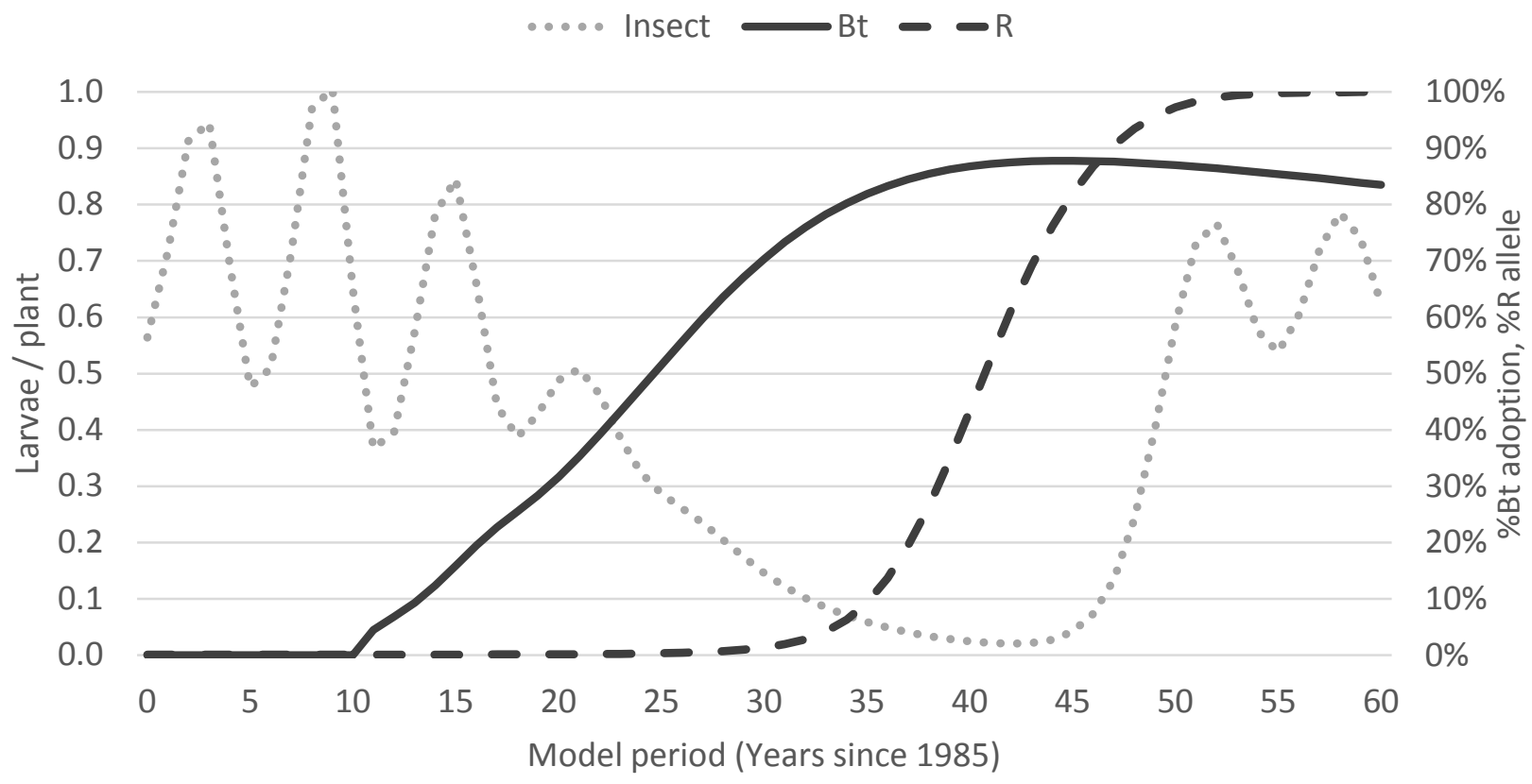

Figure 3. Baseline results for the insect population density (Insect), Bt seed adoption rate (Bt), and the resistance allele frequency (R) for the calibrated model with social networks (results for each period are averages of 1,000 simulations)

This article is protected by copyright. All rights reserved. 


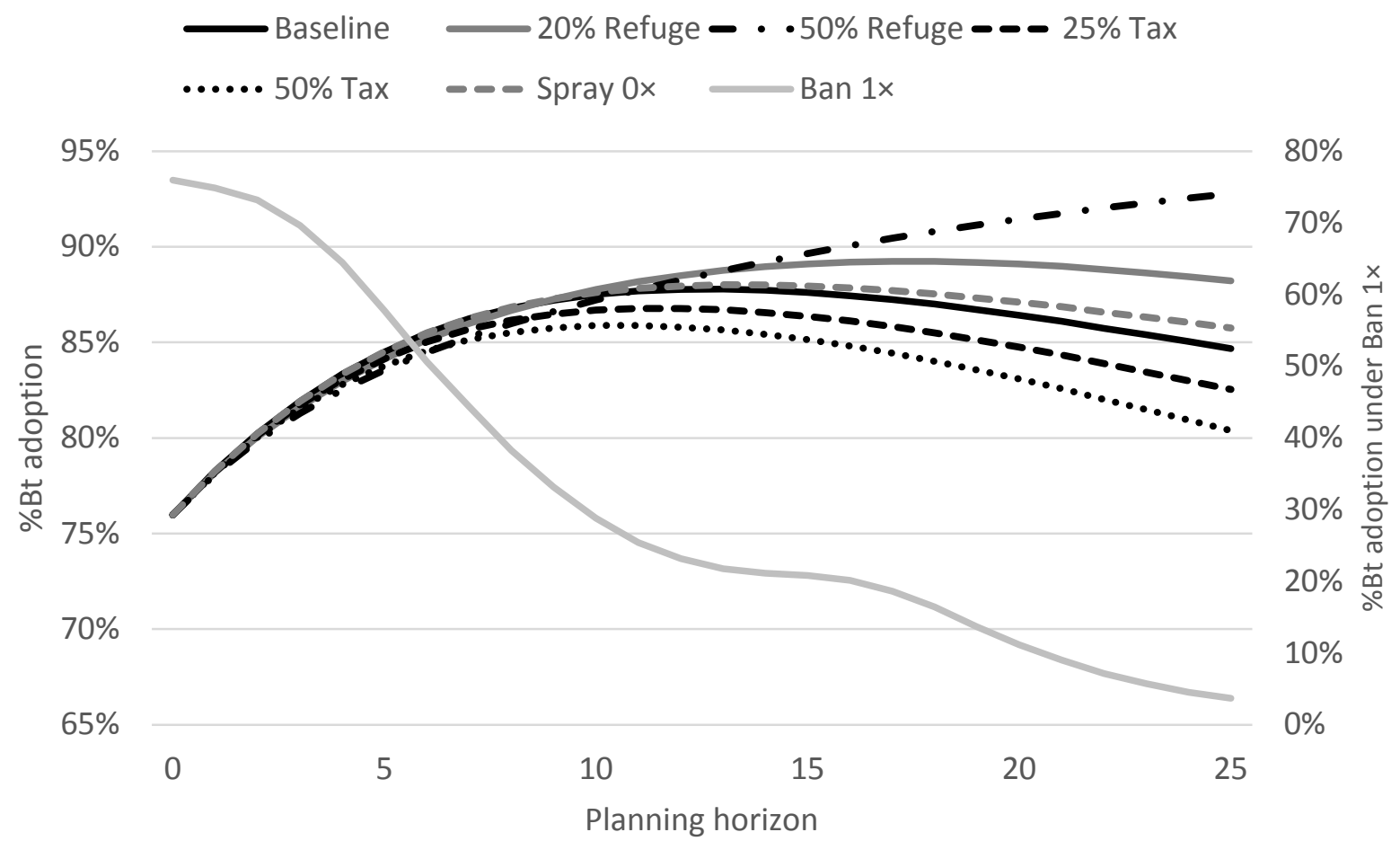

Figure 4. Bt adoption rate under single policies plotted against the planning horizon for the calibrated model with social networks (results for each period are averages of 1,000 simulations) (Scenario abbreviations denote policy changed from Baseline of 5\% refuge, with no areawide insecticidal sprays, localized Bt maize bans, or Bt seed taxes; including increasing refuge to $20 \%$ or $50 \%$ (20\% Refuge, $50 \%$ Refuge), increasing Bt seed tax to $25 \%$ or 50\% (25\% Tax, 50\% Tax), using insecticidal sprays in the field with resistance (Spray 0x) or banning use of Bt maize in fields within one dispersal radius of fields with resistance $($ Ban 1x))

This article is protected by copyright. All rights reserved. 


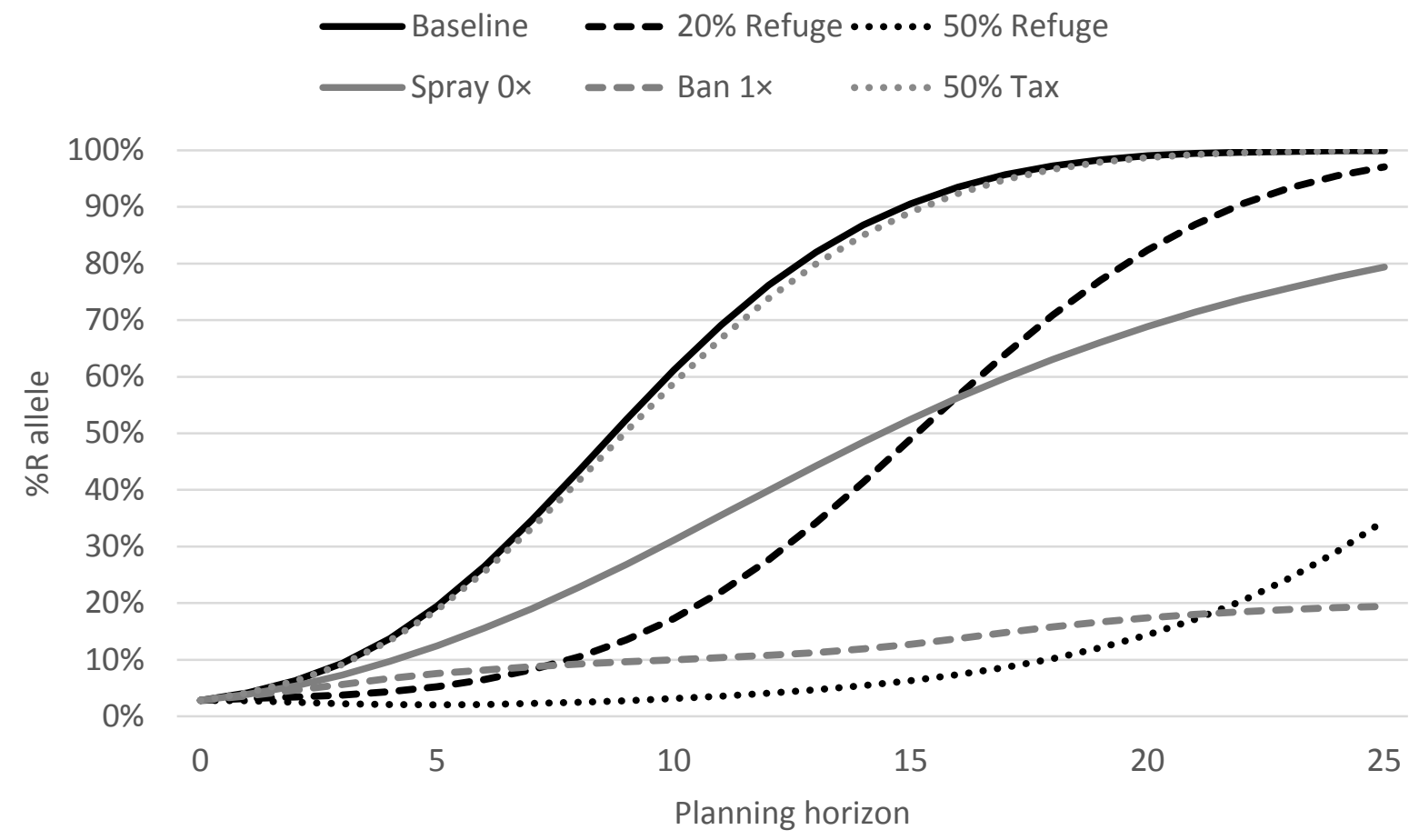

Figure 5. R-allele frequency under single policies plotted against the planning horizon for the calibrated model with social networks (results for each period are averages of 1,000 simulations) (Scenario abbreviations denote policy changed from Baseline)

This article is protected by copyright. All rights reserved. 


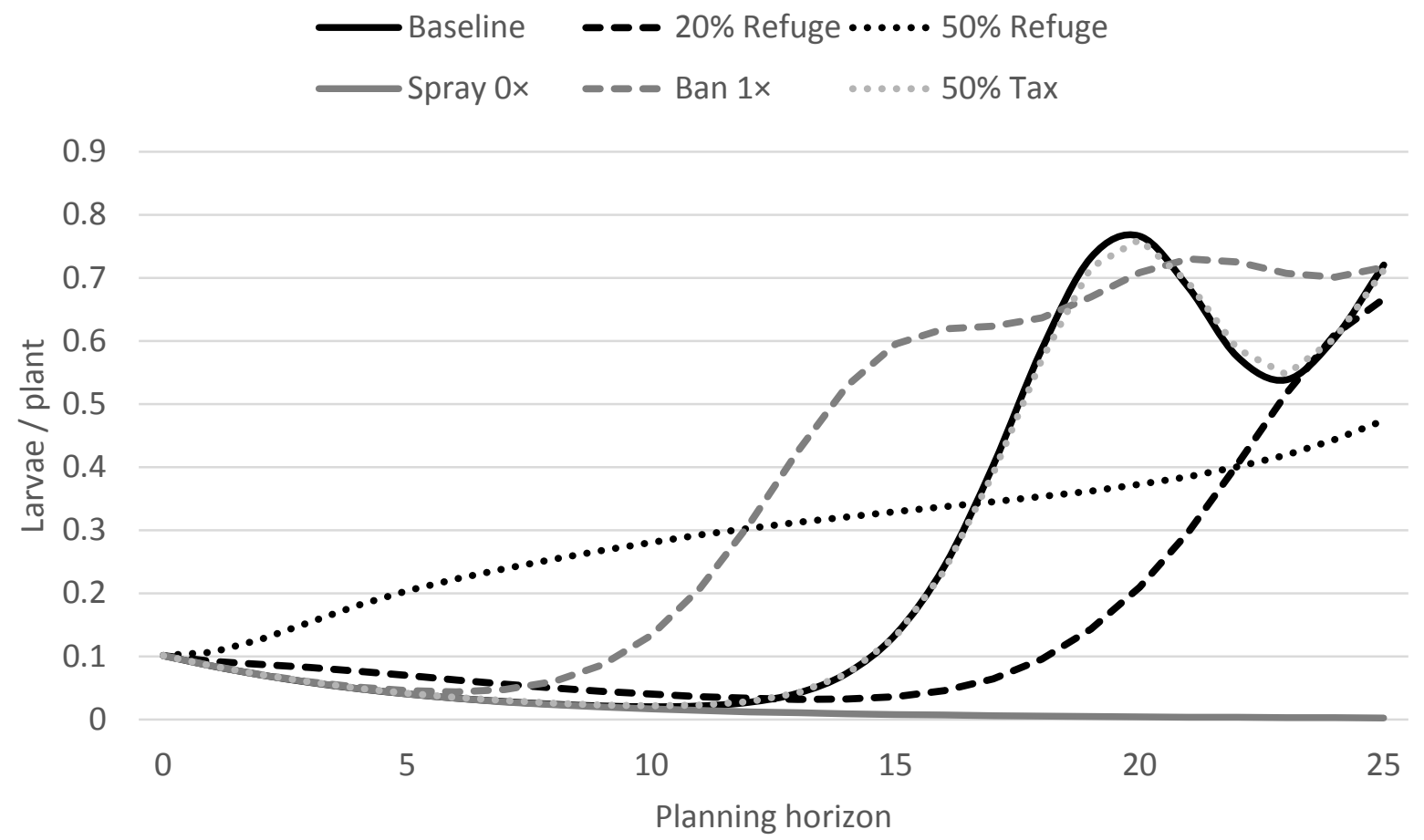

Figure 6. Insect population density under simple policies plotted against the planning horizon for the calibrated model with social networks (results for each period are averages of 1,000 simulations) (Scenario abbreviations denote policy changed from Baseline)

This article is protected by copyright. All rights reserved. 


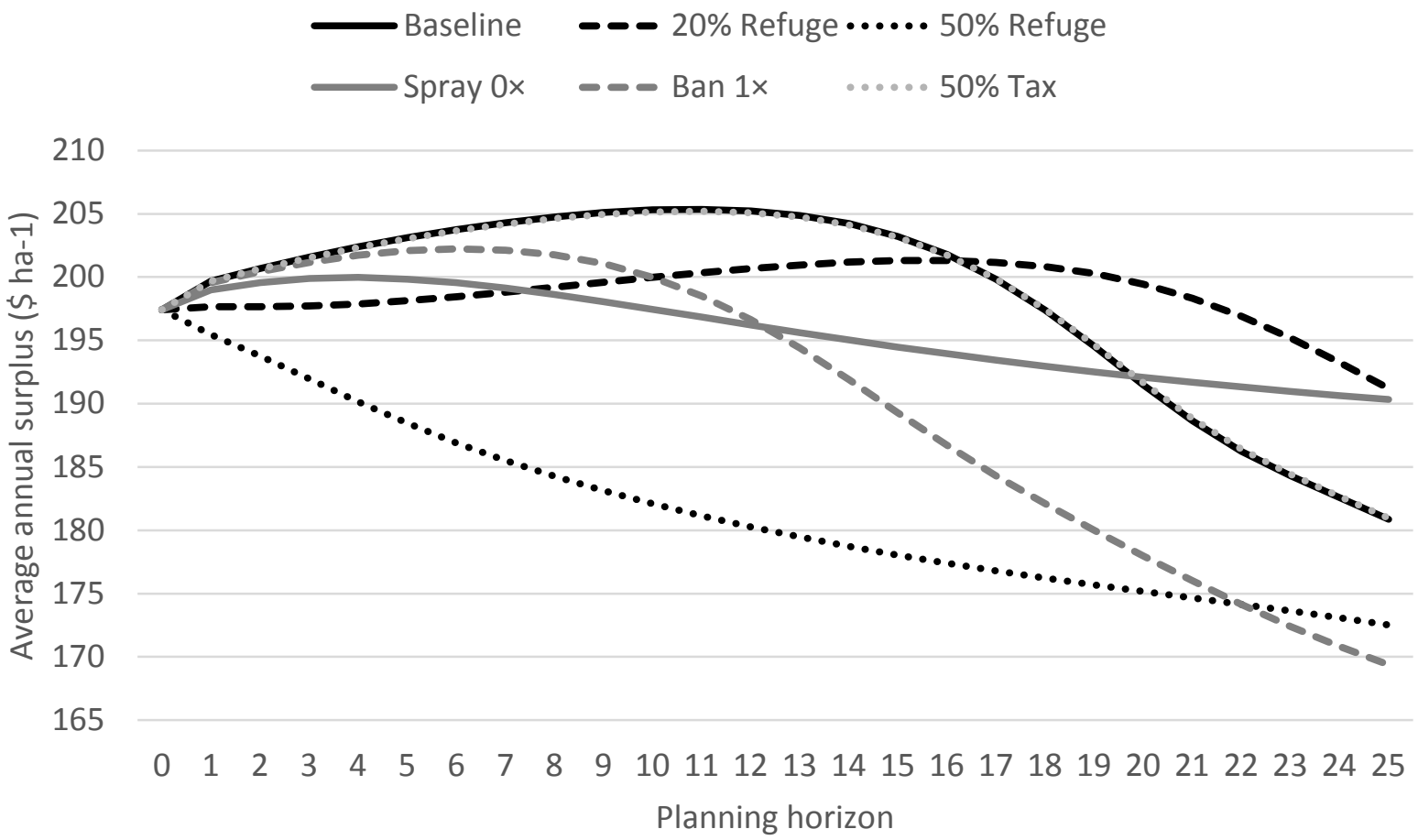

Figure 7. Average annual surplus (nominal, undiscounted) for different mitigation policies plotted against the planning horizon for the calibrated model with social networks (Scenario abbreviations denote policy changed from Baseline)

This article is protected by copyright. All rights reserved. 


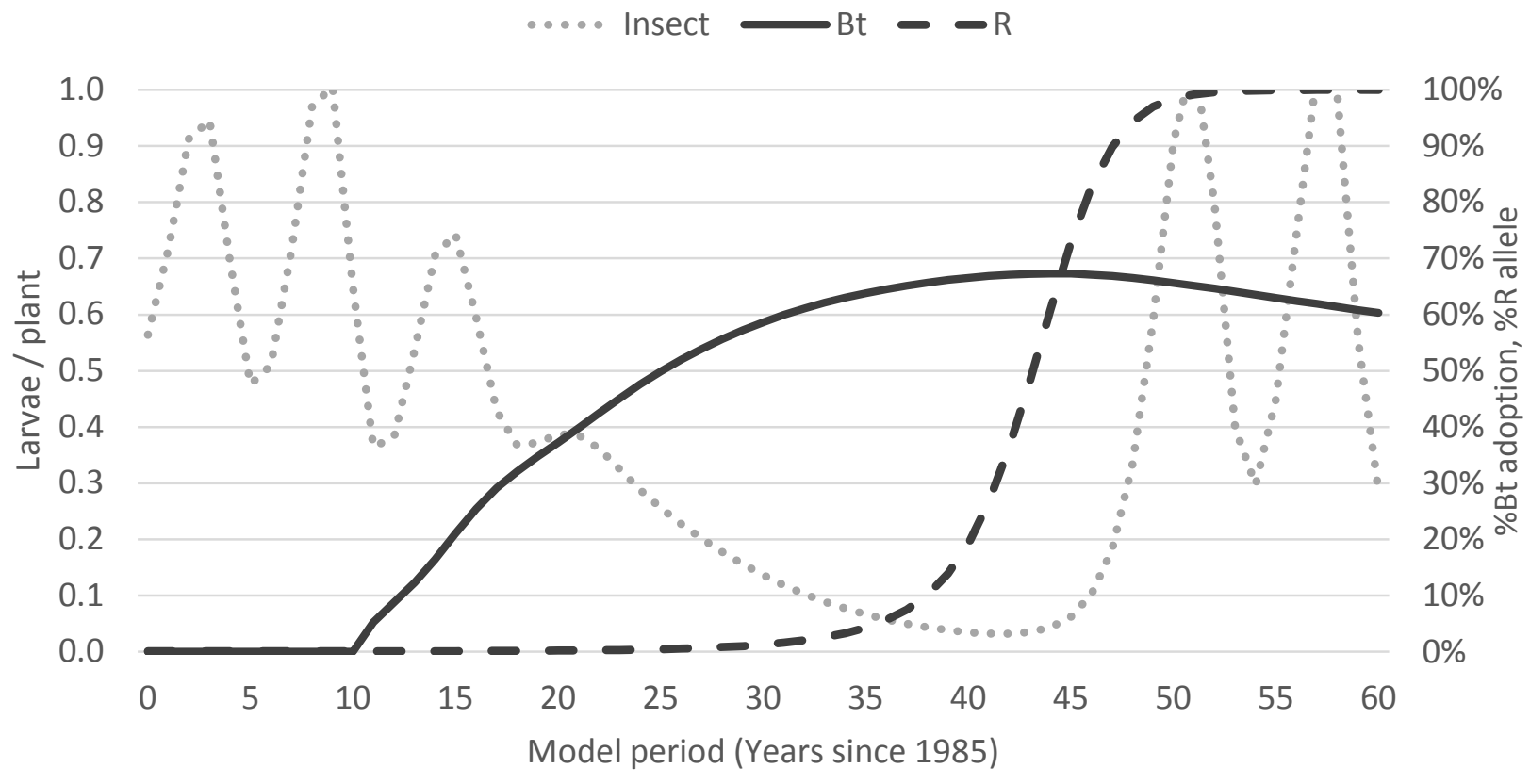

Figure 8. Results for the insect population density (Insect), Bt seed adoption rate (Bt), and the resistance allele frequency (R) for the calibrated model without social networks (results for each period are averages of 1,000 simulations) (Scenario abbreviations denote policy changed from Baseline)

This article is protected by copyright. All rights reserved. 


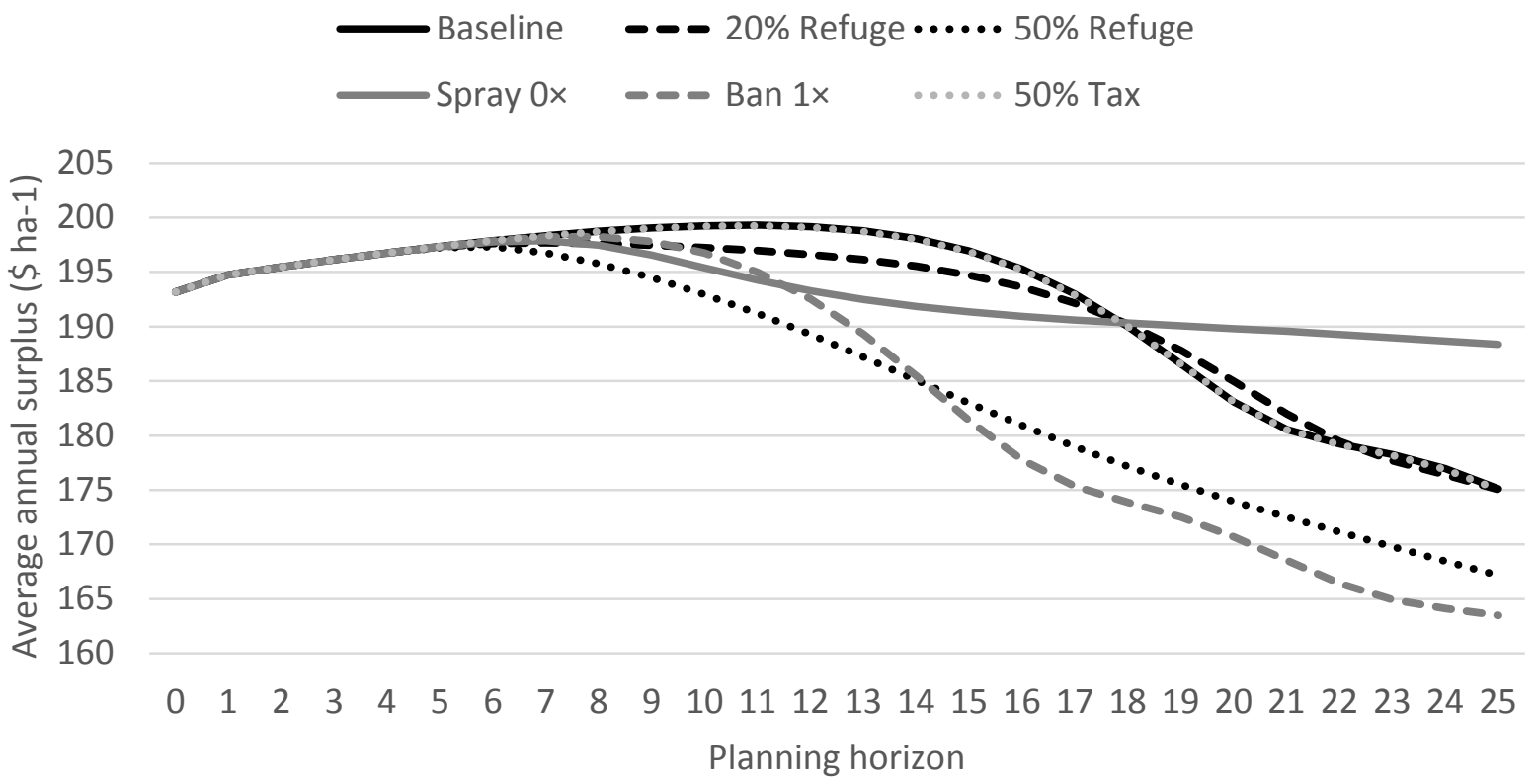

Figure 9. Average annual surplus (nominal, undiscounted) for different mitigation policies plotted against the planning horizon for the calibrated model without social networks (Scenario abbreviations denote policy changed from Baseline)

This article is protected by copyright. All rights reserved. 


\begin{tabular}{|c|c|c|c|c|c|c|c|c|c|c|c|c|c|c|c|}
\hline$\bullet$ & $\bullet$ & & & 0 & 0 & 0 & & & & & & • & & & \\
\hline$\bullet$ & & & & & & 0 & 0 & & 0 & 0 & 0 & & & $\bullet$ & $\bullet$ \\
\hline & & & & & & & 0 & & & 0 & 0 & & & & \\
\hline & & 0 & 0 & & & $\bullet$ & 0 & & & 0 & 0 & • & ○ & $\bullet$ & \\
\hline & & 0 & 0 & & & • & • & • & & & & & & $\bullet$ & \\
\hline$\bullet$ & & & & & & & $\bullet$ & 0 & 0 & & 0 & & 0 & 0 & $\bullet$ \\
\hline$\bullet$ & & & & 0 & & & & & & $\bullet$ & $\bullet$ & & $\bullet$ & $\bullet$ & $\bullet$ \\
\hline$\bullet$ & 0 & & & 0 & 0 & 0 & & & & & $\bullet$ & 0 & & & \\
\hline
\end{tabular}

Figure 1. Example model landscape. Circle $(0)$ represents a field planted to non-Bt maize, black dot ( ) represents a field planted to Bt maize, and lightgray ( $\square$ ) indicates a field with a pest population with a resistance allele frequency of more than $50 \%$ before adult dispersal.

This article is protected by copyright. All rights reserved. 


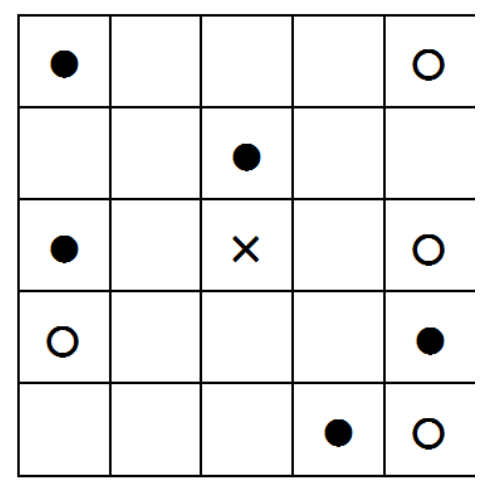

Figure 2. Example size-2 neighborhood centered on a farmer $(\mathbf{x})$ with nine neighbors who plant maize, either Bt maize (O) or non-Bt maize (O)

This article is protected by copyright. All rights reserved. 


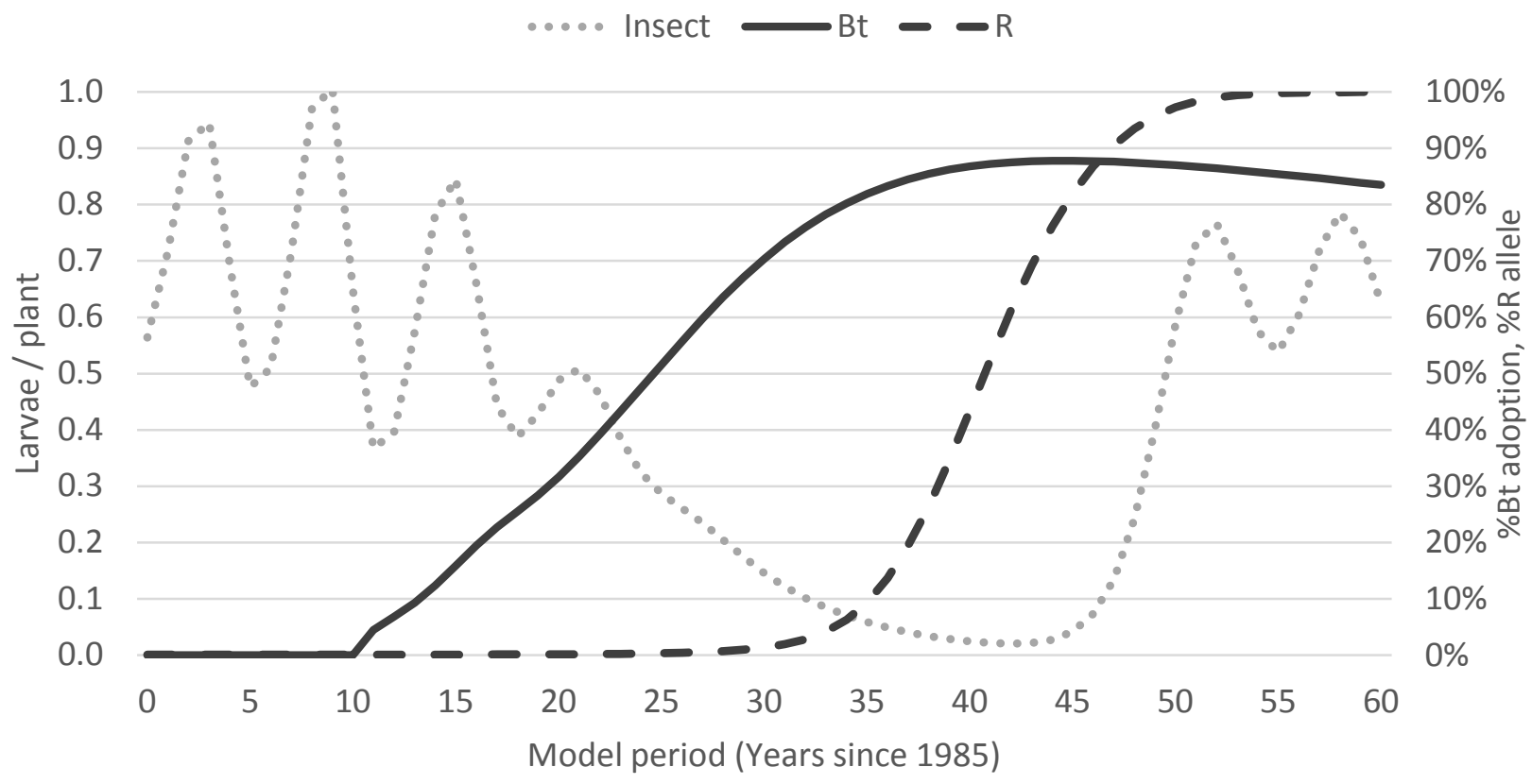

Figure 3. Baseline results for the insect population density (Insect), Bt seed adoption rate (Bt), and the resistance allele frequency (R) for the calibrated model with social networks (results for each period are averages of 1,000 simulations)

This article is protected by copyright. All rights reserved. 


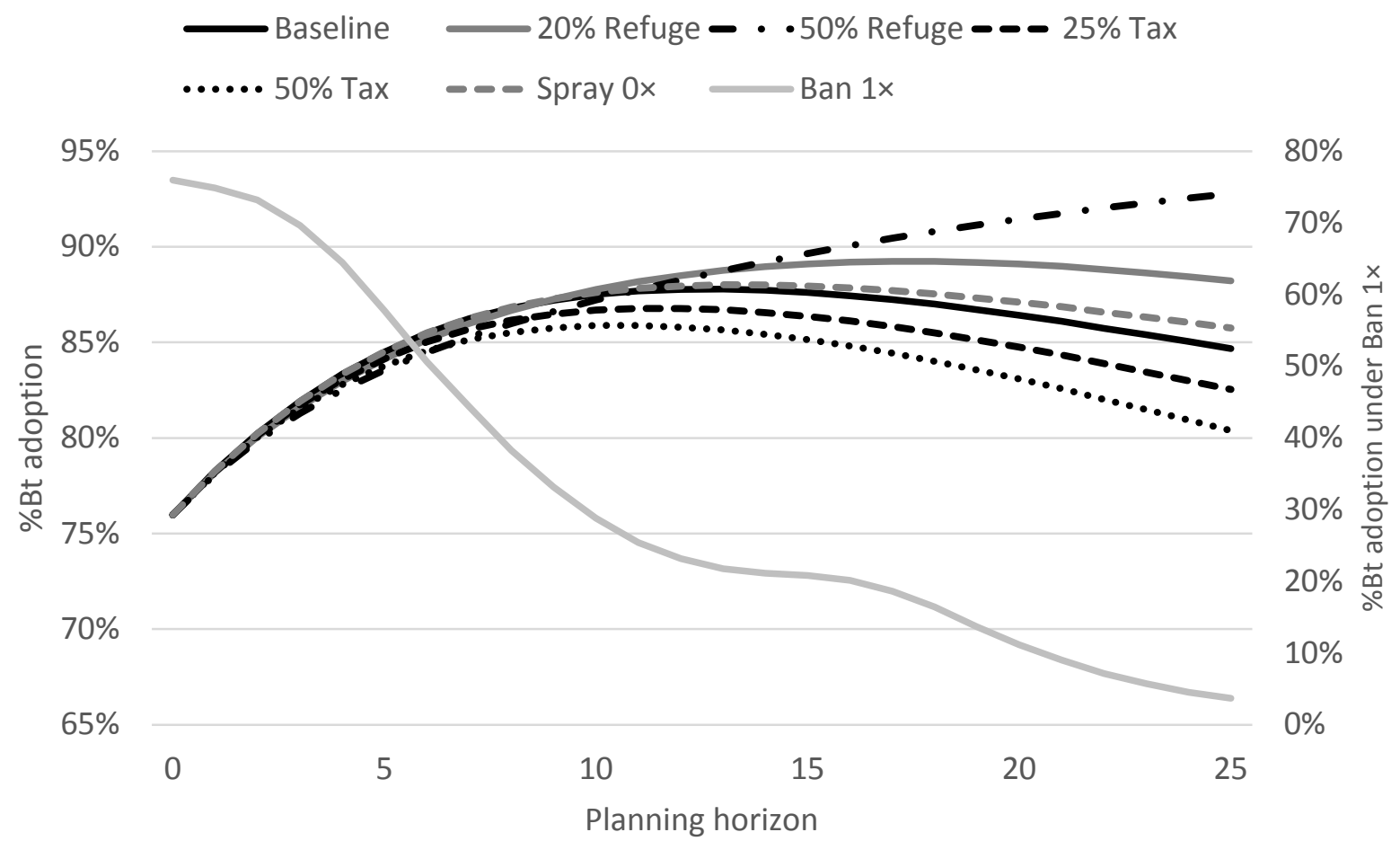

Figure 4. Bt adoption rate under single policies plotted against the planning horizon for the calibrated model with social networks (results for each period are averages of 1,000 simulations) (Scenario abbreviations denote policy changed from Baseline of 5\% refuge, with no areawide insecticidal sprays, localized Bt maize bans, or Bt seed taxes; including increasing refuge to $20 \%$ or $50 \%$ (20\% Refuge, $50 \%$ Refuge), increasing Bt seed tax to $25 \%$ or $50 \%$ (25\% Tax, 50\% Tax), using insecticidal sprays in the field with resistance (Spray 0x) or banning use of Bt maize in fields within one dispersal radius of fields with resistance $($ Ban 1x))

This article is protected by copyright. All rights reserved. 


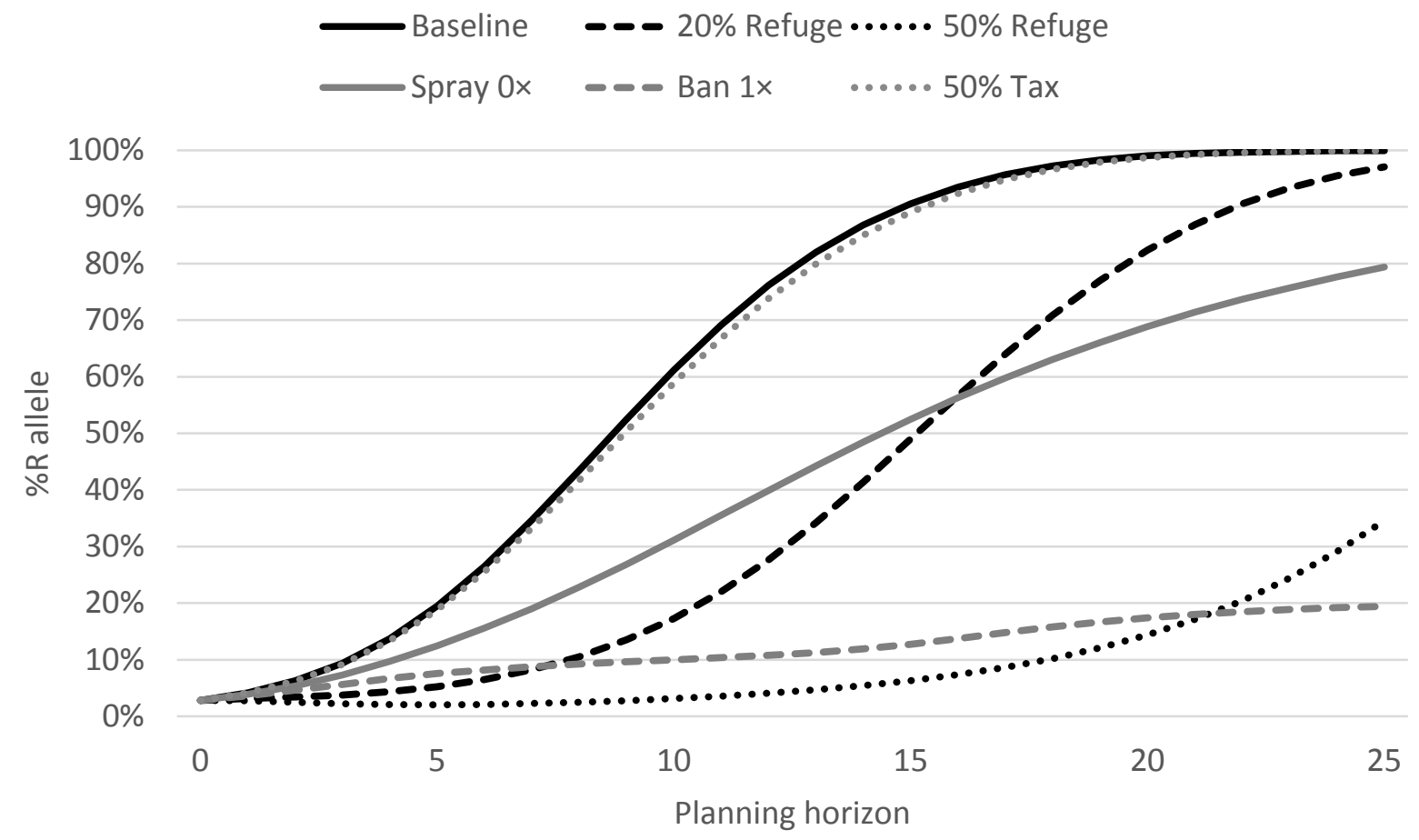

Figure 5. R-allele frequency under single policies plotted against the planning horizon for the calibrated model with social networks (results for each period are averages of 1,000 simulations) (Scenario abbreviations denote policy changed from Baseline)

This article is protected by copyright. All rights reserved. 


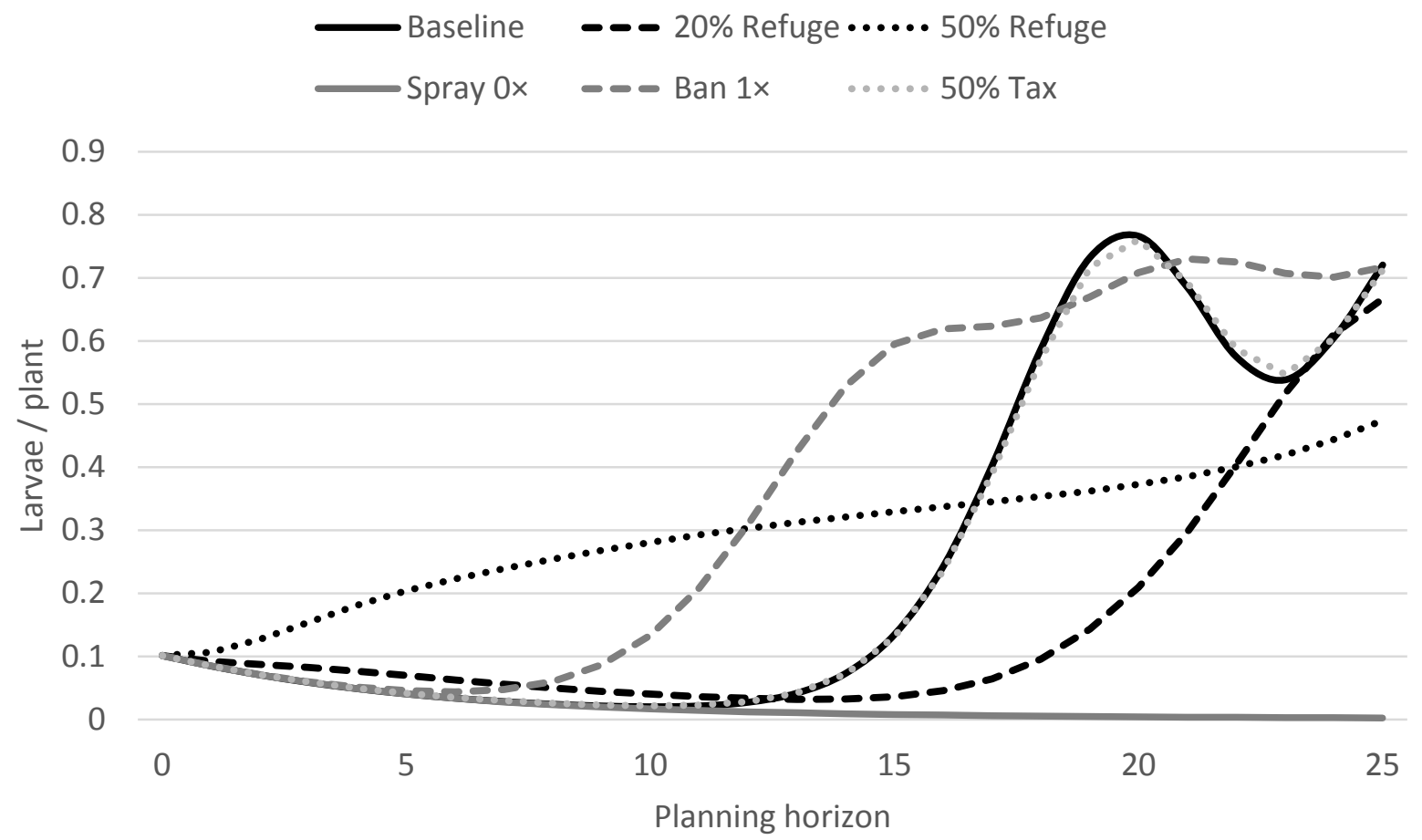

Figure 6. Insect population density under simple policies plotted against the planning horizon for the calibrated model with social networks (results for each period are averages of 1,000 simulations) (Scenario abbreviations denote policy changed from Baseline)

This article is protected by copyright. All rights reserved. 


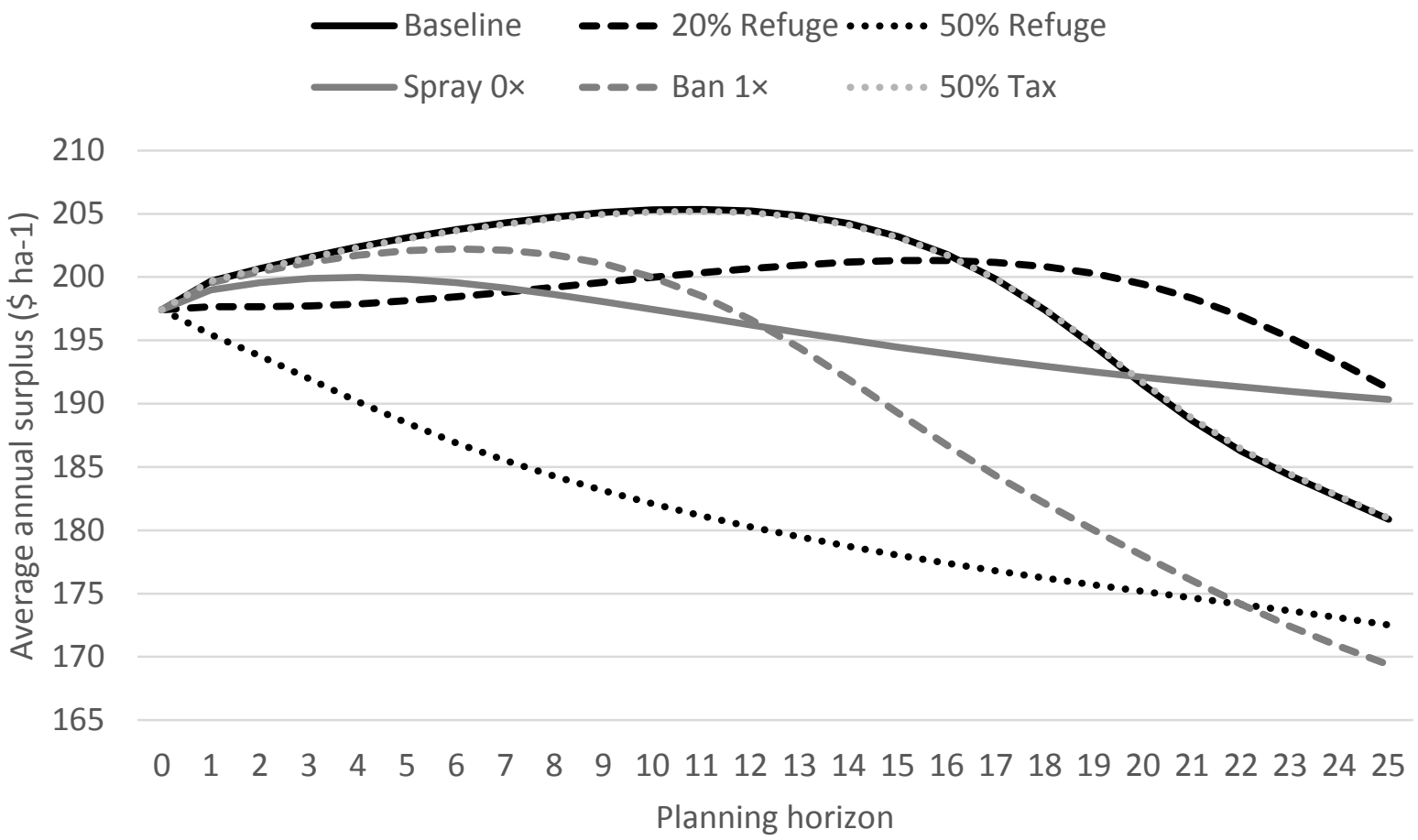

Figure 7. Average annual surplus (nominal, undiscounted) for different mitigation policies plotted against the planning horizon for the calibrated model with social networks (Scenario abbreviations denote policy changed from Baseline)

This article is protected by copyright. All rights reserved. 


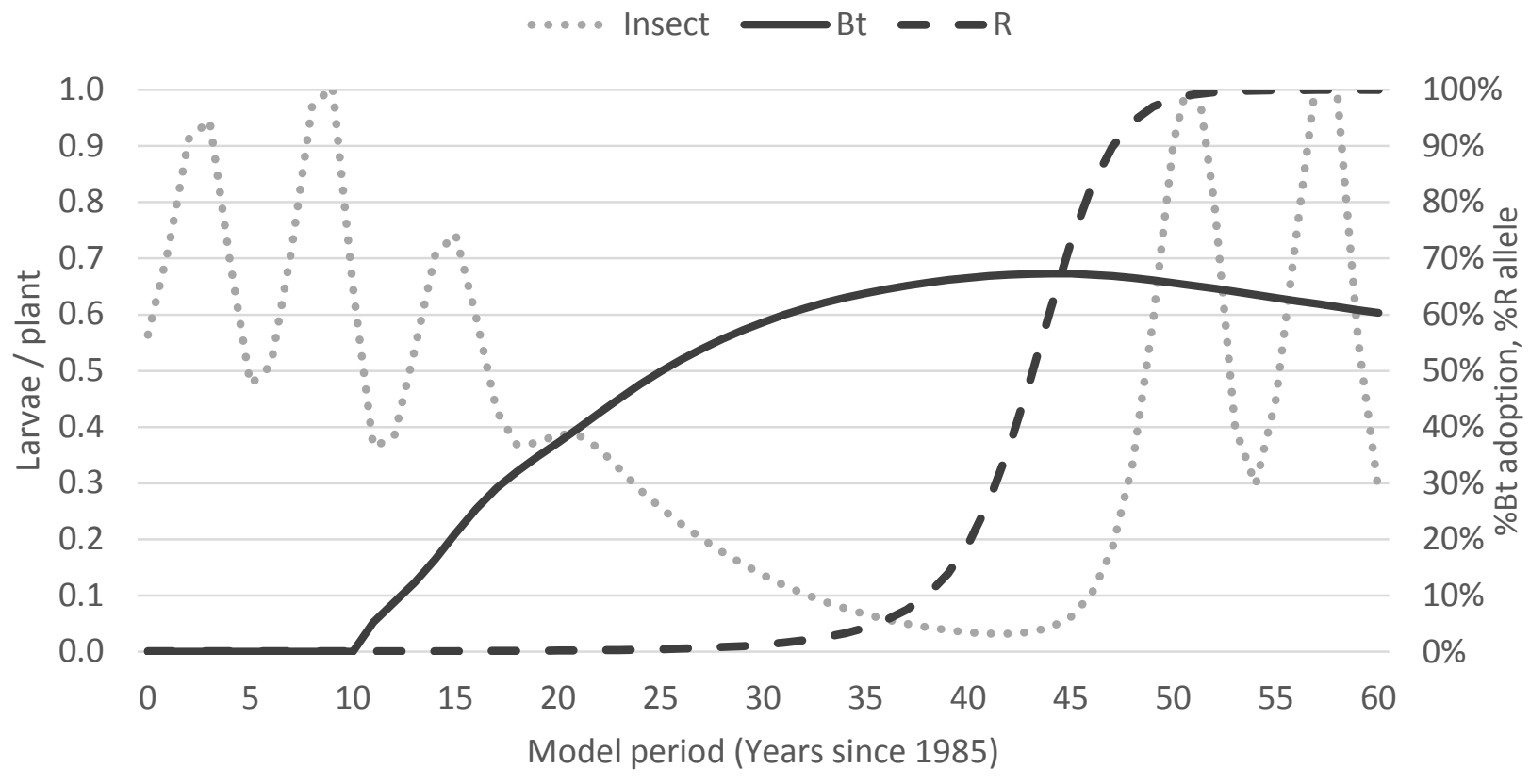

Figure 8. Results for the insect population density (Insect), Bt seed adoption rate (Bt), and the resistance allele frequency (R) for the calibrated model without social networks (results for each period are averages of 1,000 simulations) (Scenario abbreviations denote policy changed from Baseline)

This article is protected by copyright. All rights reserved. 


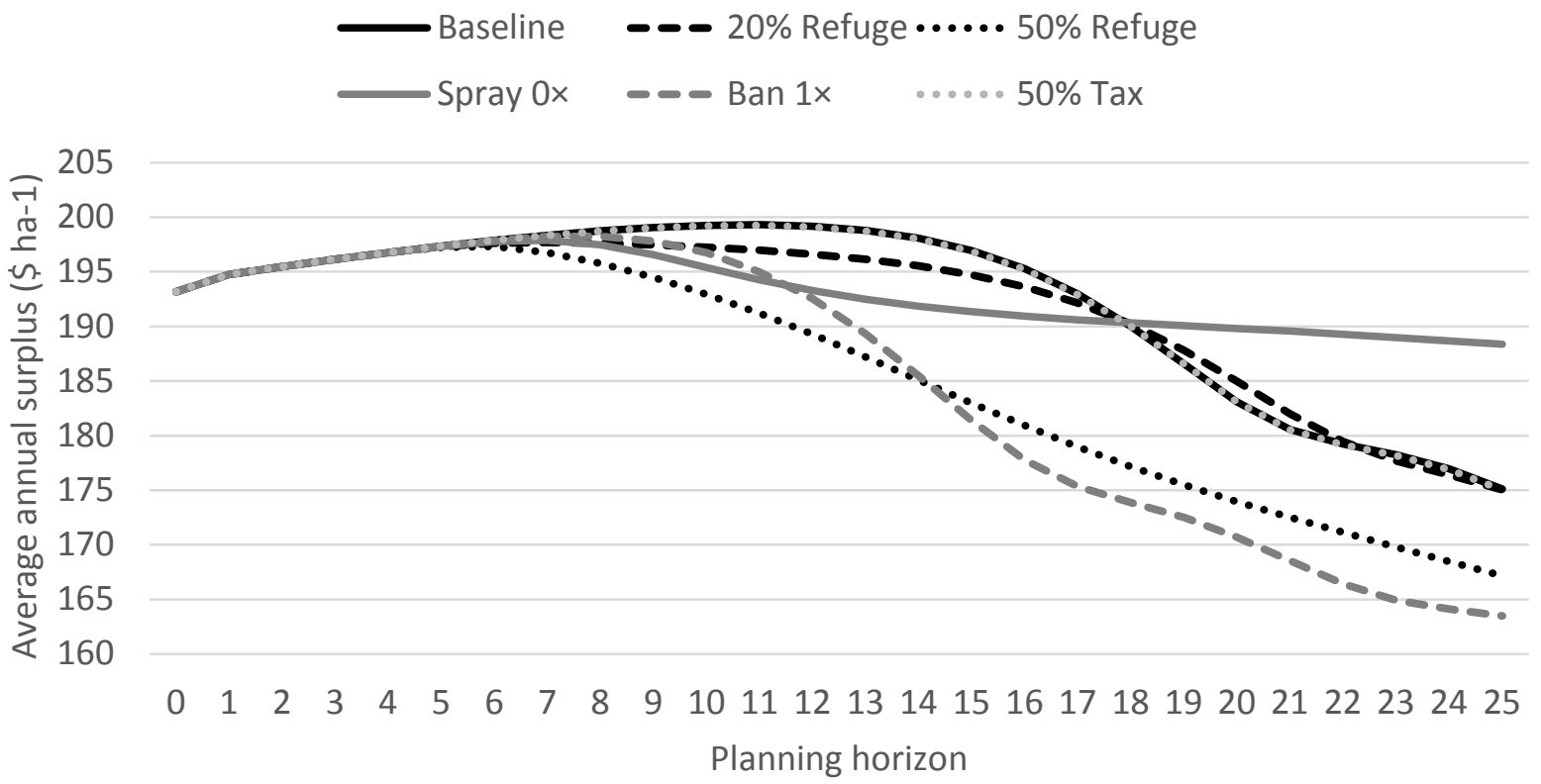

Figure 9. Average annual surplus (nominal, undiscounted) for different mitigation policies plotted against the planning horizon for the calibrated model without social networks (Scenario abbreviations denote policy changed from Baseline)

This article is protected by copyright. All rights reserved. 


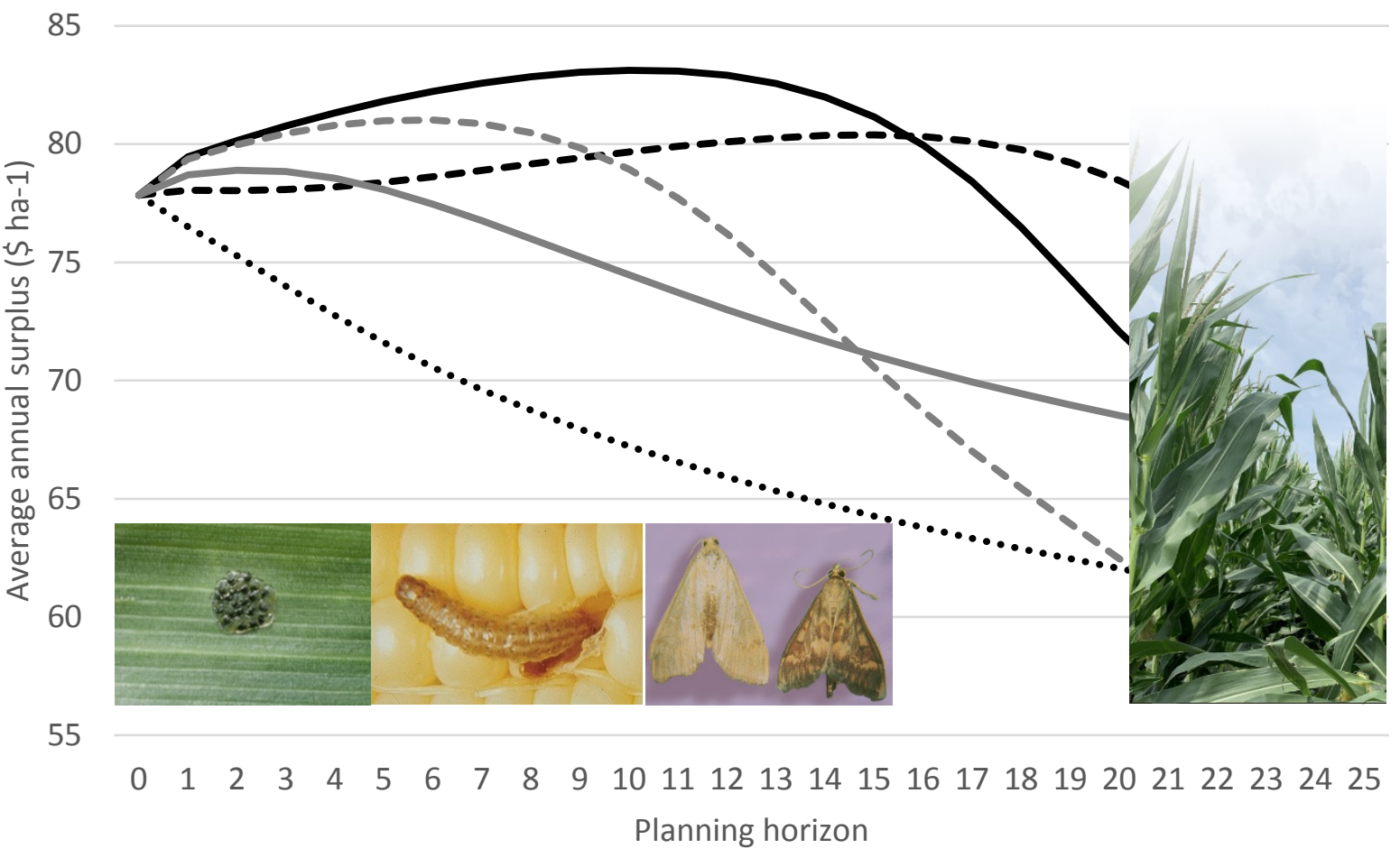

\section{Graphical Abstract}

This paper describes a spatially explicit population genetics model of resistance to Bt toxins by the insect Ostrinia nubilalis and an agent-based model of farmer adoption of Bt maize incorporating social networks. 


\section{University Library}

\section{- M M I N E R VA A gateway to Melbourne's research publications}

Minerva Access is the Institutional Repository of The University of Melbourne

Author/s:

Saikai, Y;Hurley, TM;Mitchell, PD

Title:

An agent-based model of insect resistance management and mitigation for Bt maize: a social science perspective

Date:

2020-08-16

\section{Citation:}

Saikai, Y., Hurley, T. M. \& Mitchell, P. D. (2020). An agent-based model of insect resistance management and mitigation for Bt maize: a social science perspective. Pest Management Science, 77 (1), pp.273-284. https://doi.org/10.1002/ps.6016.

Persistent Link:

http://hdl.handle.net/11343/276149 